\title{
THE FUTURE OF EMPLOYMENT: HOW SUSCEPTIBLE ARE JOBS TO COMPUTERISATION?*
}

\author{
Carl Benedikt Frey ${ }^{\dagger}$ and Michael A. Osborne ${ }^{\ddagger}$
}

September 17, 2013

\begin{abstract}
We examine how susceptible jobs are to computerisation. To assess this, we begin by implementing a novel methodology to estimate the probability of computerisation for 702 detailed occupations, using a Gaussian process classifier. Based on these estimates, we examine expected impacts of future computerisation on US labour market outcomes, with the primary objective of analysing the number of jobs at risk and the relationship between an occupation's probability of computerisation, wages and educational attainment. According to our estimates, about 47 percent of total US employment is at risk. We further provide evidence that wages and educational attainment exhibit a strong negative relationship with an occupation's probability of computerisation.
\end{abstract}

Keywords: Occupational Choice, Technological Change, Wage Inequality, Employment, Skill Demand

JEL Classification: E24, J24, J31, J62, O33.

*We thank the Oxford University Engineering Sciences Department and the Oxford Martin Programme on the Impacts of Future Technology for hosting the "Machines and Employment" Workshop. We are indebted to Stuart Armstrong, Nick Bostrom, Eris Chinellato, Mark Cummins, Daniel Dewey, David Dorn, Alex Flint, Claudia Goldin, John Muellbauer, Vincent Mueller, Paul Newman, Seán Ó hÉigeartaigh, Anders Sandberg, Murray Shanahan, and Keith Woolcock for their excellent suggestions.

$\dagger$ Oxford Martin School, Programme on the Impacts of Future Technology, University of Oxford, Oxford, OX1 1PT, United Kingdom, carl.frey@philosophy.ox.ac.uk.

${ }^{\ddagger}$ Department of Engineering Science, University of Oxford, Oxford, OX1 3PJ, United Kingdom, mosb@robots.ox.ac.uk. 


\section{INTRODUCTION}

In this paper, we address the question: how susceptible are jobs to computerisation? Doing so, we build on the existing literature in two ways. First, drawing upon recent advances in Machine Learning (ML) and Mobile Robotics (MR), we develop a novel methodology to categorise occupations according to their susceptibility to computerisation. ${ }^{1}$ Second, we implement this methodology to estimate the probability of computerisation for 702 detailed occupations, and examine expected impacts of future computerisation on US labour market outcomes.

Our paper is motivated by John Maynard Keynes's frequently cited prediction of widespread technological unemployment "due to our discovery of means of economising the use of labour outrunning the pace at which we can find new uses for labour" (Keynes, 1933, p. 3). Indeed, over the past decades, computers have substituted for a number of jobs, including the functions of bookkeepers, cashiers and telephone operators (Bresnahan, 1999; MGI, 2013). More recently, the poor performance of labour markets across advanced economies has intensified the debate about technological unemployment among economists. While there is ongoing disagreement about the driving forces behind the persistently high unemployment rates, a number of scholars have pointed at computercontrolled equipment as a possible explanation for recent jobless growth (see, for example, Brynjolfsson and McAfee, 2011). ${ }^{2}$

The impact of computerisation on labour market outcomes is well-established in the literature, documenting the decline of employment in routine intensive occupations - i.e. occupations mainly consisting of tasks following well-defined procedures that can easily be performed by sophisticated algorithms. For example, studies by Charles, et al. (2013) and Jaimovich and Siu (2012) emphasise that the ongoing decline in manufacturing employment and the disappearance of other routine jobs is causing the current low rates of employment. ${ }^{3}$ In ad-

\footnotetext{
${ }^{1}$ We refer to computerisation as job automation by means of computer-controlled equipment.

${ }^{2}$ This view finds support in a recent survey by the McKinsey Global Institute (MGI), showing that 44 percent of firms which reduced their headcount since the financial crisis of 2008 had done so by means of automation (MGI, 2011).

${ }^{3}$ Because the core job tasks of manufacturing occupations follow well-defined repetitive procedures, they can easily be codified in computer software and thus performed by computers (Acemoglu and Autor, 2011).
} 
dition to the computerisation of routine manufacturing tasks, Autor and Dorn (2013) document a structural shift in the labour market, with workers reallocating their labour supply from middle-income manufacturing to low-income service occupations. Arguably, this is because the manual tasks of service occupations are less susceptible to computerisation, as they require a higher degree of flexibility and physical adaptability (Autor, et al., 2003; Goos and Manning, 2007; Autor and Dorn, 2013).

At the same time, with falling prices of computing, problem-solving skills are becoming relatively productive, explaining the substantial employment growth in occupations involving cognitive tasks where skilled labour has a comparative advantage, as well as the persistent increase in returns to education (Katz and Murphy, 1992; Acemoglu, 2002; Autor and Dorn, 2013). The title "Lousy and Lovely Jobs", of recent work by Goos and Manning (2007), thus captures the essence of the current trend towards labour market polarization, with growing employment in high-income cognitive jobs and low-income manual occupations, accompanied by a hollowing-out of middle-income routine jobs.

According to Brynjolfsson and McAfee (2011), the pace of technological innovation is still increasing, with more sophisticated software technologies disrupting labour markets by making workers redundant. What is striking about the examples in their book is that computerisation is no longer confined to routine manufacturing tasks. The autonomous driverless cars, developed by Google, provide one example of how manual tasks in transport and logistics may soon be automated. In the section "In Domain After Domain, Computers Race Ahead", they emphasise how fast moving these developments have been. Less than ten years ago, in the chapter "Why People Still Matter", Levy and Murnane (2004) pointed at the difficulties of replicating human perception, asserting that driving in traffic is insusceptible to automation: "But executing a left turn against oncoming traffic involves so many factors that it is hard to imagine discovering the set of rules that can replicate a driver's behaviour [...]". Six years later, in October 2010, Google announced that it had modified several Toyota Priuses to be fully autonomous (Brynjolfsson and McAfee, 2011).

To our knowledge, no study has yet quantified what recent technological progress is likely to mean for the future of employment. The present study intends to bridge this gap in the literature. Although there are indeed existing 
useful frameworks for examining the impact of computers on the occupational employment composition, they seem inadequate in explaining the impact of technological trends going beyond the computerisation of routine tasks. Seminal work by Autor, et al. (2003), for example, distinguishes between cognitive and manual tasks on the one hand, and routine and non-routine tasks on the other. While the computer substitution for both cognitive and manual routine tasks is evident, non-routine tasks involve everything from legal writing, truck driving and medical diagnoses, to persuading and selling. In the present study, we will argue that legal writing and truck driving will soon be automated, while persuading, for instance, will not. Drawing upon recent developments in Engineering Sciences, and in particular advances in the fields of ML, including Data Mining, Machine Vision, Computational Statistics and other sub-fields of Artificial Intelligence, as well as MR, we derive additional dimensions required to understand the susceptibility of jobs to computerisation. Needless to say, a number of factors are driving decisions to automate and we cannot capture these in full. Rather we aim, from a technological capabilities point of view, to determine which problems engineers need to solve for specific occupations to be automated. By highlighting these problems, their difficulty and to which occupations they relate, we categorise jobs according to their susceptibility to computerisation. The characteristics of these problems were matched to different occupational characteristics, using $\mathrm{O} * \mathrm{NET}$ data, allowing us to examine the future direction of technological change in terms of its impact on the occupational composition of the labour market, but also the number of jobs at risk should these technologies materialise.

The present study relates to two literatures. First, our analysis builds on the labour economics literature on the task content of employment (Autor, et al., 2003; Goos and Manning, 2007; Autor and Dorn, 2013). Based on defined premises about what computers do, this literature examines the historical impact of computerisation on the occupational composition of the labour market. However, the scope of what computers do has recently expanded, and will inevitably continue to do so (Brynjolfsson and McAfee, 2011; MGI, 2013). Drawing upon recent progress in ML, we expand the premises about the tasks computers are and will be suited to accomplish. Doing so, we build on the task content literature in a forward-looking manner. Furthermore, whereas this literature has largely focused on task measures from the Dictionary of Occupational 
Titles (DOT), last revised in 1991, we rely on the 2010 version of the DOT successor $\mathrm{O} * \mathrm{NET}-$ an online service developed for the US Department of Labor. ${ }^{4}$ Accordingly, $\mathrm{O} * \mathrm{NET}$ has the advantage of providing more recent information on occupational work activities.

Second, our study relates to the literature examining the offshoring of information-based tasks to foreign worksites (Jensen and Kletzer, 2005; Blinder, 2009; Jensen and Kletzer, 2010; Oldenski, 2012; Blinder and Krueger, 2013). This literature consists of different methodologies to rank and categorise occupations according to their susceptibility to offshoring. For example, using $\mathrm{O} *$ NET data on the nature of work done in different occupations, Blinder (2009) estimates that 22 to 29 percent of US jobs are or will be offshorable in the next decade or two. These estimates are based on two defining characteristics of jobs that cannot be offshored: (a) the job must be performed at a specific work location; and (b) the job requires face-to-face personal communication. Naturally, the characteristics of occupations that can be offshored are different from the characteristics of occupations that can be automated. For example, the work of cashiers, which has largely been substituted by self- service technology, must be performed at specific work location and requires face-to-face contact. The extent of computerisation is therefore likely to go beyond that of offshoring. Hence, while the implementation of our methodology is similar to that of Blinder (2009), we rely on different occupational characteristics.

The remainder of this paper is structured as follows. In Section II, we review the literature on the historical relationship between technological progress and employment. Section III describes recent and expected future technological developments. In Section IV, we describe our methodology, and in Section V, we examine the expected impact of these technological developments on labour market outcomes. Finally, in Section VI, we derive some conclusions.

\section{A HISTORY OF TECHNOLOGICAL REVOLUTIONS AND EMPLOYMENT}

The concern over technological unemployment is hardly a recent phenomenon. Throughout history, the process of creative destruction, following technological inventions, has created enormous wealth, but also undesired disruptions. As stressed by Schumpeter (1962), it was not the lack of inventive ideas that

\footnotetext{
${ }^{4}$ An exception is Goos, et al. (2009).
} 
set the boundaries for economic development, but rather powerful social and economic interests promoting the technological status quo. This is nicely illustrated by the example of William Lee, inventing the stocking frame knitting machine in 1589, hoping that it would relieve workers of hand-knitting. Seeking patent protection for his invention, he travelled to London where he had rented a building for his machine to be viewed by Queen Elizabeth I. To his disappointment, the Queen was more concerned with the employment impact of his invention and refused to grant him a patent, claiming that: "Thou aimest high, Master Lee. Consider thou what the invention could do to my poor subjects. It would assuredly bring to them ruin by depriving them of employment, thus making them beggars" (cited in Acemoglu and Robinson, 2012, p. 182f). Most likely the Queen's concern was a manifestation of the hosiers' guilds fear that the invention would make the skills of its artisan members obsolete. ${ }^{5}$ The guilds' opposition was indeed so intense that William Lee had to leave Britain.

That guilds systematically tried to weaken market forces as aggregators to maintain the technological status quo is persuasively argued by Kellenbenz (1974, p. 243), stating that "guilds defended the interests of their members against outsiders, and these included the inventors who, with their new equipment and techniques, threatened to disturb their members' economic status." 6 As pointed out by Mokyr (1998, p. 11): "Unless all individuals accept the "verdict" of the market outcome, the decision whether to adopt an innovation is likely to be resisted by losers through non-market mechanism and political activism." Workers can thus be expected to resist new technologies, insofar that they make their skills obsolete and irreversibly reduce their expected earnings. The balance between job conservation and technological progress therefore, to a large extent, reflects the balance of power in society, and how gains from technological progress are being distributed.

The British Industrial Revolution illustrates this point vividly. While still widely present on the Continent, the craft guild in Britain had, by the time of

\footnotetext{
${ }^{5}$ The term artisan refers to a craftsman who engages in the entire production process of a good, containing almost no division of labour. By guild we mean an association of artisans that control the practice of their craft in a particular town.

${ }^{6}$ There is an ongoing debate about the technological role of the guilds. Epstein (1998), for example, has argued that they fulfilled an important role in the intergenerational transmission of knowledge. Yet there is no immediate contradiction between such a role and their conservative stand on technological progress: there are clear examples of guilds restraining the diffusion of inventions (see, for example, Ogilvie, 2004).
} 
the Glorious Revolution of 1688, declined and lost most of its political clout (Nef, 1957, pp. 26 and 32). With Parliamentary supremacy established over the Crown, legislation was passed in 1769 making the destruction of machinery punishable by death (Mokyr, 1990, p. 257). To be sure, there was still resistance to mechanisation. The "Luddite" riots between 1811 and 1816 were partly a manifestation of the fear of technological change among workers as Parliament revoked a 1551 law prohibiting the use of gig mills in the wool-finishing trade. The British government however took an increasingly stern view on groups attempting to halt technological progress and deployed 12,000 men against the rioters (Mantoux, 2006, p. 403-8). The sentiment of the government towards the destruction of machinery was explained by a resolution passed after the Lancashire riots of 1779 , stating that: "The sole cause of great riots was the new machines employed in cotton manufacture; the country notwithstanding has greatly benefited from their erection [and] destroying them in this country would only be the means of transferring them to another [...] to the detriment of the trade of Britain" (cited in Mantoux, 2006, p. 403).

There are at least two possible explanations for the shift in attitudes towards technological progress. First, after Parliamentary supremacy was established over the Crown, the property owning classes became politically dominant in Britain (North and Weingast, 1989). Because the diffusion of various manufacturing technologies did not impose a risk to the value of their assets, and some property owners stood to benefit from the export of manufactured goods, the artisans simply did not have the political power to repress them. Second, inventors, consumers and unskilled factory workers largely benefited from mechanisation (Mokyr, 1990, p. 256 and 258). It has even been argued that, despite the employment concerns over mechanisation, unskilled workers have been the greatest beneficiaries of the Industrial Revolution (Clark, 2008). ${ }^{7}$ While there

\footnotetext{
${ }^{7}$ Various estimations of the living standards of workers in Britain during the industrialisation exist in the literature. For example, Clark (2008) finds that real wages over the period 1760 to 1860 rose faster than GDP per capita. Further evidence provided by Lindert and Williamson (1983) even suggests that real wages nearly doubled between 1820 and 1850. Feinstein (1998), on the other hand, finds a much more moderate increase, with average working-class living standards improving by less than 15 percent between 1770 and 1870. Finally, Allen (2009a) finds that over the first half of the nineteenth century, the real wage stagnated while output per worker expanded. After the mid nineteenth century, however, real wages began to grow in line with productivity. While this implies that capital owners were the greatest beneficiaries of the Industrial Revolution, there is at the same time consensus that average living standards largely improved.
} 
is contradictory evidence suggesting that capital owners initially accumulated a growing share of national income (Allen, 2009a), there is equally evidence of growing real wages (Lindert and Williamson, 1983; Feinstein, 1998). This implies that although manufacturing technologies made the skills of artisans obsolete, gains from technological progress were distributed in a manner that gradually benefited a growing share of the labour force. ${ }^{8}$

An important feature of nineteenth century manufacturing technologies is that they were largely "deskilling" - i.e. they substituted for skills through the simplification of tasks (Braverman, 1974; Hounshell, 1985; James and Skinner, 1985; Goldin and Katz, 1998). The deskilling process occurred as the factory system began to displace the artisan shop, and it picked up pace as production increasingly mechanized with the adoption of steam power (Goldin and Sokoloff, 1982; Atack, et al., 2008a). Work that had previously been performed by artisans was now decomposed into smaller, highly specialised, sequences, requiring less skill, but more workers, to perform. ${ }^{9}$ Some innovations were even designed to be deskilling. For example, Eli Whitney, a pioneer of interchangeable parts, described the objective of this technology as "to substitute correct and effective operations of machinery for the skill of the artist which is acquired only by long practice and experience; a species of skill which is not possessed in this country to any considerable extent" (Habakkuk, 1962, p. 22).

Together with developments in continuous-flow production, enabling workers to be stationary while different tasks were moved to them, it was identical interchangeable parts that allowed complex products to be assembled from mass produced individual components by using highly specialised machine tools to

\footnotetext{
${ }^{8}$ The term skill is associated with higher levels of education, ability, or job training. Following Goldin and Katz (1998), we refer to technology-skill or capital-skill complementarity when a new technology or physical capital complements skilled labour relative to unskilled workers.

${ }^{9}$ The production of plows nicely illustrates the differences between the artisan shop and the factory. In one artisan shop, two men spent 118 man-hours using hammers, anvils, chisels, hatchets, axes, mallets, shaves and augers in 11 distinct operations to produce a plow. By contrast, a mechanized plow factory employed 52 workers performing 97 distinct tasks, of which 72 were assisted by steam power, to produce a plow in just 3.75 man-hours. The degree of specialization was even greater in the production of men's white muslin shirts. In the artisan shop, one worker spent 1439 hours performing 25 different tasks to produce 144 shirts. In the factory, it took 188 man-hours to produce the same quantity, engaging 230 different workers performing 39 different tasks, of which more than half required steam power. The workers involved included cutters, turners and trimmers, as well as foremen and forewomen, inspectors, errand boys, an engineer, a fireman, and a watchman (US Department of Labor, 1899).
} 
a sequence of operations. ${ }^{10}$ Yet while the first assembly-line was documented in 1804, it was not until the late nineteenth century that continuous-flow processes started to be adopted on a larger scale, which enabled corporations such as the Ford Motor Company to manufacture the T-Ford at a sufficiently low price for it to become the people's vehicle (Mokyr, 1990, p. 137). Crucially, the new assembly line introduced by Ford in 1913 was specifically designed for machinery to be operated by unskilled workers (Hounshell, 1985, p. 239). Furthermore, what had previously been a one-man job was turned into a 29-man worker operation, reducing the overall work time by 34 percent (Bright, 1958). The example of the Ford Motor Company thus underlines the general pattern observed in the nineteenth century, with physical capital providing a relative complement to unskilled labour, while substituting for relatively skilled artisans (James and Skinner, 1985; Louis and Paterson, 1986; Brown and Philips, 1986; Atack, et al., 2004). ${ }^{11}$ Hence, as pointed out by Acemoglu (2002, p. 7): "the idea that technological advances favor more skilled workers is a twentieth century phenomenon." The conventional wisdom among economic historians, in other words, suggests a discontinuity between the nineteenth and twentieth century in the impact of capital deepening on the relative demand for skilled labour.

The modern pattern of capital-skill complementarity gradually emerged in the late nineteenth century, as manufacturing production shifted to increasingly mechanised assembly lines. This shift can be traced to the switch to electricity from steam and water-power which, in combination with continuous-process

\footnotetext{
${ }^{10}$ These machines were sequentially implemented until the production process was completed. Over time, such machines became much cheaper relative to skilled labor. As a result, production became much more capital intensive (Hounshell, 1985).

${ }^{11}$ Williamson and Lindert (1980), on the other hand, find a relative rise in wage premium of skilled labour over the period 1820 to 1860 , which they partly attribute to capital deepening. Their claim of growing wage inequality over this period has, however, been challenged (Margo, 2000). Yet seen over the long-run, a more refined explanation is that the manufacturing share of the labour force in the nineteenth century hollowed out. This is suggested by recent findings, revealing a decline of middle-skill artisan jobs in favour of both high-skill white collar workers and low-skill operatives (Gray, 2013; Katz and Margo, 2013). Furthermore, even if the share of operatives was increasing due to organizational change within manufacturing and overall manufacturing growth, it does not follow that the share of unskilled labor was rising in the aggregate economy, because some of the growth in the share of operatives may have come at the expense of a decrease in the share of workers employed as low-skilled farm workers in agriculture (Katz and Margo, 2013). Nevertheless, this evidence is consistent with the literature showing that relatively skilled artisans were replaced by unskilled factory workers, suggesting that technological change in manufacturing was deskilling.
} 
and batch production methods, reduced the demand for unskilled manual workers in many hauling, conveying, and assembly tasks, but increased the demand for skills (Goldin and Katz, 1998). In short, while factory assembly lines, with their extreme division of labour, had required vast quantities of human operatives, electrification allowed many stages of the production process to be automated, which in turn increased the demand for relatively skilled blue-collar production workers to operate the machinery. In addition, electrification contributed to a growing share of white-collar nonproduction workers (Goldin and Katz, 1998). Over the course of the nineteenth century, establishments became larger in size as steam and water power technologies improved, allowing them to adopt powered machinery to realize productivity gains through the combination of enhanced division of labour and higher capital intensity (Atack, et al., 2008a). Furthermore, the transport revolution lowered costs of shipping goods domestically and internationally as infrastructure spread and improved (Atack, et $a l ., 2008 b$ ). The market for artisan goods early on had largely been confined to the immediate surrounding area because transport costs were high relative to the value of the goods produced. With the transport revolution, however, market size expanded, thereby eroding local monopoly power, which in turn increased competition and compelled firms to raise productivity through mechanisation. As establishments became larger and served geographically expended markets, managerial tasks increased in number and complexity, requiring more managerial and clerking employees (Chandler, 1977). This pattern was, by the turn of the twentieth century, reinforced by electrification, which not only contributed to a growing share of relatively skilled blue-collar labour, but also increased the demand for white-collar workers (Goldin and Katz, 1998), who tended to have higher educational attainment (Allen, 2001). ${ }^{12}$

Since electrification, the story of the twentieth century has been the race between education and technology (Goldin and Katz, 2009). The US high school movement coincided with the first industrial revolution of the office (Goldin and Katz, 1995). While the typewriter was invented in the 1860s, it was not introduced in the office until the early twentieth century, when it entered a wave

\footnotetext{
${ }^{12}$ Most likely, the growing share of white-collar workers increased the element of human interaction in employment. Notably, Michaels, et al. (2013) find that the increase in the employment share of interactive occupations, going hand in hand with an increase in their relative wage bill share, was particularly strong between 1880 and 1930, which is a period of rapid change in communication and transport technology.
} 
of mechanisation, with dictaphones, calculators, mimeo machines, address machines, and the predecessor of the computer - the keypunch (Beniger, 1986; Cortada, 2000). Importantly, these office machines reduced the cost of information processing tasks and increased the demand for the complementary factori.e. educated office workers. Yet the increased supply of educated office workers, following the high school movement, was associated with a sharp decline in the wage premium of clerking occupations relative to production workers (Goldin and Katz, 1995). This was, however, not the result of deskilling technological change. Clerking workers were indeed relatively educated. Rather, it was the result of the supply of educated workers outpacing the demand for their skills, leading educational wage differentials to compress.

While educational wage differentials in the US narrowed from 1915 to 1980 (Goldin and Katz, 2009), both educational wage differentials and overall wage inequality have increased sharply since the 1980s in a number of countries (Krueger, 1993; Murphy, et al., 1998; Atkinson, 2008; Goldin and Katz, 2009). Although there are clearly several variables at work, consensus is broad that this can be ascribed to an acceleration in capital-skill complementarity, driven by the adoption of computers and information technology (Krueger, 1993; Autor, et al., 1998; Bresnahan, et al., 2002). What is commonly referred to as the Computer Revolution began with the first commercial uses of computers around 1960 and continued through the development of the Internet and e-commerce in the 1990s. As the cost per computation declined at an annual average of 37 percent between 1945 and 1980 (Nordhaus, 2007), telephone operators were made redundant, the first industrial robot was introduced by General Motors in the 1960s, and in the 1970s airline reservations systems led the way in selfservice technology (Gordon, 2012). During the 1980s and 1990s, computing costs declined even more rapidly, on average by 64 percent per year, accompanied by a surge in computational power (Nordhaus, 2007). ${ }^{13}$ At the same time, bar-code scanners and cash machines were spreading across the retail and financial industries, and the first personal computers were introduced in the early 1980s, with their word processing and spreadsheet functions eliminating copy typist occupations and allowing repetitive calculations to be automated (Gordon, 2012). This substitution for labour marks a further important reversal.

\footnotetext{
${ }^{13}$ Computer power even increased 18 percent faster on annual basis than predicted by Moore's Law, implying a doubling every two years (Nordhaus, 2007).
} 
The early twentieth century office machines increased the demand for clerking workers (Chandler, 1977; Goldin and Katz, 1995). In a similar manner, computerisation augments demand for such tasks, but it also permits them to be automated (Autor, et al., 2003).

The Computer Revolution can go some way in explaining the growing wage inequality of the past decades. For example, Krueger (1993) finds that workers using a computer earn roughly earn 10 to 15 percent more than others, but also that computer use accounts for a substantial share of the increase in the rate of return to education. In addition, more recent studies find that computers have caused a shift in the occupational structure of the labour market. Autor and Dorn (2013), for example, show that as computerisation erodes wages for labour performing routine tasks, workers will reallocate their labour supply to relatively low-skill service occupations. More specifically, between 1980 and 2005, the share of US labour hours in service occupations grew by 30 percent after having been flat or declining in the three prior decades. Furthermore, net changes in US employment were U-shaped in skill level, meaning that the lowest and highest job-skill quartile expanded sharply with relative employment declines in the middle of the distribution.

The expansion in high-skill employment can be explained by the falling price of carrying out routine tasks by means of computers, which complements more abstract and creative services. Seen from a production function perspective, an outward shift in the supply of routine informational inputs increases the marginal productivity of workers they are demanded by. For example, text and data mining has improved the quality of legal research as constant access to market information has improved the efficiency of managerial decision-making - i.e. tasks performed by skilled workers at the higher end of the income distribution. The result has been an increasingly polarised labour market, with growing employment in high-income cognitive jobs and low-income manual occupations, accompanied by a hollowing-out of middle-income routine jobs. This is a pattern that is not unique to the US and equally applies to a number of developed economies (Goos, et al., 2009). ${ }^{14}$

\footnotetext{
${ }^{14}$ While there is broad consensus that computers substituting for workers in routine-intensive tasks has driven labour market polarisation over the past decades, there are, indeed, alternative explanations. For example, technological advances in computing have dramatically lowered the cost of leaving information-based tasks to foreign worksites (Jensen and Kletzer, 2005; Blinder, 2009; Jensen and Kletzer, 2010; Oldenski, 2012; Blinder and Krueger, 2013). The decline in
} 
How technological progress in the twenty-first century will impact on labour market outcomes remains to be seen. Throughout history, technological progress has vastly shifted the composition of employment, from agriculture and the artisan shop, to manufacturing and clerking, to service and management occupations. Yet the concern over technological unemployment has proven to be exaggerated. The obvious reason why this concern has not materialised relates to Ricardo's famous chapter on machinery, which suggests that laboursaving technology reduces the demand for undifferentiated labour, thus leading to technological unemployment (Ricardo, 1819). As economists have long understood, however, an invention that replaces workers by machines will have effects on all product and factor markets. An increase in the efficiency of production which reduces the price of one good, will increase real income and thus increase demand for other goods. Hence, in short, technological progress has two competing effects on employment (Aghion and Howitt, 1994). First, as technology substitutes for labour, there is a destruction effect, requiring workers to reallocate their labour supply; and second, there is the capitalisation effect, as more companies enter industries where productivity is relatively high, leading employment in those industries to expand.

Although the capitalisation effect has been predominant historically, our discovery of means of economising the use of labour can outrun the pace at which we can find new uses for labour, as Keynes (1933) pointed out. The reason why human labour has prevailed relates to its ability to adopt and acquire new skills by means of education (Goldin and Katz, 2009). Yet as computerisation enters more cognitive domains this will become increasingly challenging (Brynjolfsson and McAfee, 2011). Recent empirical findings are therefore particularly concerning. For example, Beaudry, et al. (2013) document a decline in the demand for skill over the past decade, even as the supply of workers with higher education has continued to grow. They show that high-skilled workers have moved down the occupational ladder, taking on jobs traditionally performed by low-skilled workers, pushing low-skilled workers even further down the occupational ladder and, to some extent, even out of the labour force. This

the routine-intensity of employment is thus likely to result from a combination of offshoring and automation. Furthermore, there is evidence suggesting that improvements in transport and communication technology have augmented occupations involving human interaction, spanning across both cognitive and manual tasks (Michaels, et al., 2013). These explanations are nevertheless equally related to advance in computing and communications technology. 
raises questions about: (a) the ability of human labour to win the race against technology by means of education; and (b) the potential extent of technological unemployment, as an increasing pace of technological progress will cause higher job turnover, resulting in a higher natural rate of unemployment (Lucas and Prescott, 1974; Davis and Haltiwanger, 1992; Pissarides, 2000). While the present study is limited to examining the destruction effect of technology, it nevertheless provides a useful indication of the job growth required to counterbalance the jobs at risk over the next decades.

\section{THE TECHNOLOGICAL REVOLUTIONS OF THE TWENTY-FIRST CENTURY}

The secular price decline in the real cost of computing has created vast economic incentives for employers to substitute labour for computer capital. ${ }^{15}$ Yet the tasks computers are able to perform ultimately depend upon the ability of a programmer to write a set of procedures or rules that appropriately direct the technology in each possible contingency. Computers will therefore be relatively productive to human labour when a problem can be specified - in the sense that the criteria for success are quantifiable and can readily be evaluated (Acemoglu and Autor, 2011). The extent of job computerisation will thus be determined by technological advances that allow engineering problems to be sufficiently specified, which sets the boundaries for the scope of computerisation. In this section, we examine the extent of tasks computer-controlled equipment can be expected to perform over the next decades. Doing so, we focus on advances in fields related to Machine Learning (ML), including Data Mining, Machine Vision, Computational Statistics and other sub-fields of Artificial Intelligence (AI), in which efforts are explicitly dedicated to the development of algorithms that allow cognitive tasks to be automated. In addition, we examine the application of ML technologies in Mobile Robotics (MR), and thus the extent of computerisation in manual tasks.

Our analysis builds on the task categorisation of Autor, et al. (2003), which distinguishes between workplace tasks using a two-by-two matrix, with routine versus non-routine tasks on one axis, and manual versus cognitive tasks on the other. In short, routine tasks are defined as tasks that follow explicit rules that

\footnotetext{
${ }^{15} \mathrm{We}$ refer to computer capital as accumulated computers and computer-controlled equipment by means of capital deepening.
} 
can be accomplished by machines, while non-routine tasks are not sufficiently well understood to be specified in computer code. Each of these task categories can, in turn, be of either manual or cognitive nature - i.e. they relate to physical labour or knowledge work. Historically, computerisation has largely been confined to manual and cognitive routine tasks involving explicit rulebased activities (Autor and Dorn, 2013; Goos, et al., 2009). Following recent technological advances, however, computerisation is now spreading to domains commonly defined as non-routine. The rapid pace at which tasks that were defined as non-routine only a decade ago have now become computerisable is illustrated by Autor, et al. (2003), asserting that: "Navigating a car through city traffic or deciphering the scrawled handwriting on a personal check - minor undertakings for most adults - are not routine tasks by our definition." Today, the problems of navigating a car and deciphering handwriting are sufficiently well understood that many related tasks can be specified in computer code and automated (Veres, et al., 2011; Plötz and Fink, 2009).

Recent technological breakthroughs are, in large part, due to efforts to turn non-routine tasks into well-defined problems. Defining such problems is helped by the provision of relevant data: this is highlighted in the case of handwriting recognition by Plötz and Fink (2009). The success of an algorithm for handwriting recognition is difficult to quantify without data to test on - in particular, determining whether an algorithm performs well for different styles of writing requires data containing a variety of such styles. That is, data is required to specify the many contingencies a technology must manage in order to form an adequate substitute for human labour. With data, objective and quantifiable measures of the success of an algorithm can be produced, which aid the continual improvement of its performance relative to humans.

As such, technological progress has been aided by the recent production of increasingly large and complex datasets, known as big data. ${ }^{16}$ For instance, with a growing corpus of human-translated digitalised text, the success of a machine translator can now be judged by its accuracy in reproducing observed translations. Data from United Nations documents, which are translated by hu-

\footnotetext{
${ }^{16}$ Predictions by Cisco Systems suggest that the Internet traffic in 2016 will be around 1 zettabyte ( $1 \times 10^{21}$ bytes) (Cisco, 2012). In comparison, the information contained in all books worldwide is about 480 terabytes $\left(5 \times 10^{14}\right.$ bytes), and a text transcript of all the words ever spoken by humans would represent about 5 exabytes $\left(5 \times 10^{18}\right.$ bytes) (UC Berkeley School of Information, 2003).
} 
man experts into six languages, allow Google Translate to monitor and improve the performance of different machine translation algorithms (Tanner, 2007).

Further, ML algorithms can discover unexpected similarities between old and new data, aiding the computerisation of tasks for which big data has newly become available. As a result, computerisation is no longer confined to routine tasks that can be written as rule-based software queries, but is spreading to every non-routine task where big data becomes available (Brynjolfsson and McAfee, 2011). In this section, we examine the extent of future computerisation beyond routine tasks.

\section{III.A. Computerisation in non-routine cognitive tasks}

With the availability of big data, a wide range of non-routine cognitive tasks are becoming computerisable. That is, further to the general improvement in technological progress due to big data, algorithms for big data are rapidly entering domains reliant upon storing or accessing information. The use of big data is afforded by one of the chief comparative advantages of computers relative to human labor: scalability. Little evidence is required to demonstrate that, in performing the task of laborious computation, networks of machines scale better than human labour (Campbell-Kelly, 2009). As such, computers can better manage the large calculations required in using large datasets. ML algorithms running on computers are now, in many cases, better able to detect patterns in big data than humans.

Computerisation of cognitive tasks is also aided by another core comparative advantage of algorithms: their absence of some human biases. An algorithm can be designed to ruthlessly satisfy the small range of tasks it is given. Humans, in contrast, must fulfill a range of tasks unrelated to their occupation, such as sleeping, necessitating occasional sacrifices in their occupational performance (Kahneman, et al., 1982). The additional constraints under which humans must operate manifest themselves as biases. Consider an example of human bias: Danziger, et al. (2011) demonstrate that experienced Israeli judges are substantially more generous in their rulings following a lunch break. It can thus be argued that many roles involving decision-making will benefit from impartial algorithmic solutions.

Fraud detection is a task that requires both impartial decision making and the ability to detect trends in big data. As such, this task is now almost com- 
pletely automated (Phua, et al., 2010). In a similar manner, the comparative advantages of computers are likely to change the nature of work across a wide range of industries and occupations.

In health care, diagnostics tasks are already being computerised. Oncologists at Memorial Sloan-Kettering Cancer Center are, for example, using IBM's Watson computer to provide chronic care and cancer treatment diagnostics. Knowledge from 600,000 medical evidence reports, 1.5 million patient records and clinical trials, and two million pages of text from medical journals, are used for benchmarking and pattern recognition purposes. This allows the computer to compare each patient's individual symptoms, genetics, family and medication history, etc., to diagnose and develop a treatment plan with the highest probability of success (Cohn, 2013).

In addition, computerisation is entering the domains of legal and financial services. Sophisticated algorithms are gradually taking on a number of tasks performed by paralegals, contract and patent lawyers (Markoff, 2011). More specifically, law firms now rely on computers that can scan thousands of legal briefs and precedents to assist in pre-trial research. A frequently cited example is Symantec's Clearwell system, which uses language analysis to identify general concepts in documents, can present the results graphically, and proved capable of analysing and sorting more than 570,000 documents in two days (Markoff, 2011).

Furthermore, the improvement of sensing technology has made sensor data one of the most prominent sources of big data (Ackerman and Guizzo, 2011). Sensor data is often coupled with new ML fault- and anomaly-detection algorithms to render many tasks computerisable. A broad class of examples can be found in condition monitoring and novelty detection, with technology substituting for closed-circuit TV (CCTV) operators, workers examining equipment defects, and clinical staff responsible for monitoring the state of patients in intensive care. Here, the fact that computers lack human biases is of great value: algorithms are free of irrational bias, and their vigilance need not be interrupted by rest breaks or lapses of concentration. Following the declining costs of digital sensing and actuation, ML approaches have successfully addressed condition monitoring applications ranging from batteries (Saha, et al., 2007), to aircraft engines (King, et al., 2009), water quality (Osborne, et al., 2012) and intensive care units (ICUs) (Clifford and Clifton, 2012; Clifton, et al., 2012). Sensors can 
equally be placed on trucks and pallets to improve companies' supply chain management, and used to measure the moisture in a field of crops to track the flow of water through utility pipes. This allows for automatic meter reading, eliminating the need for personnel to gather such information. For example, the cities of Doha, São Paulo, and Beijing use sensors on pipes, pumps, and other water infrastructure to monitor conditions and manage water loss, reducing leaks by 40 to 50 percent. In the near future, it will be possible to place inexpensive sensors on light poles, sidewalks, and other public property to capture sound and images, likely reducing the number of workers in law enforcement (MGI, 2013).

Advances in user interfaces also enable computers to respond directly to a wider range of human requests, thus augmenting the work of highly skilled labour, while allowing some types of jobs to become fully automated. For example, Apple's Siri and Google Now rely on natural user interfaces to recognise spoken words, interpret their meanings, and act on them accordingly. Moreover, a company called SmartAction now provides call computerisation solutions that use ML technology and advanced speech recognition to improve upon conventional interactive voice response systems, realising cost savings of 60 to 80 percent over an outsourced call center consisting of human labour (CAA, 2012). Even education, one of the most labour intensive sectors, will most likely be significantly impacted by improved user interfaces and algorithms building upon big data. The recent growth in MOOCs (Massive Open Online Courses) has begun to generate large datasets detailing how students interact on forums, their diligence in completing assignments and viewing lectures, and their ultimate grades (Simonite, 2013; Breslow, et al., 2013). Such information, together with improved user interfaces, will allow for ML algorithms that serve as interactive tutors, with teaching and assessment strategies statistically calibrated to match individual student needs (Woolf, 2010). Big data analysis will also allow for more effective predictions of student performance, and for their suitability for post-graduation occupations. These technologies can equally be implemented in recruitment, most likely resulting in the streamlining of human resource (HR) departments.

Occupations that require subtle judgement are also increasingly susceptible to computerisation. To many such tasks, the unbiased decision making of an algorithm represents a comparative advantage over human operators. In the most 
challenging or critical applications, as in ICUs, algorithmic recommendations may serve as inputs to human operators; in other circumstances, algorithms will themselves be responsible for appropriate decision-making. In the financial sector, such automated decision-making has played a role for quite some time. AI algorithms are able to process a greater number of financial announcements, press releases, and other information than any human trader, and then act faster upon them (Mims, 2010). Services like Future Advisor similarly use AI to offer personalised financial advice at larger scale and lower cost. Even the work of software engineers may soon largely be computerisable. For example, advances in ML allow a programmer to leave complex parameter and design choices to be appropriately optimised by an algorithm (Hoos, 2012). Algorithms can further automatically detect bugs in software (Hangal and Lam, 2002; Livshits and Zimmermann, 2005; Kim, et al., 2008), with a reliability that humans are unlikely to match. Big databases of code also offer the eventual prospect of algorithms that learn how to write programs to satisfy specifications provided by a human. Such an approach is likely to eventually improve upon human programmers, in the same way that human-written compilers eventually proved inferior to automatically optimised compilers. An algorithm can better keep the whole of a program in working memory, and is not constrained to human-intelligible code, allowing for holistic solutions that might never occur to a human. Such algorithmic improvements over human judgement are likely to become increasingly common.

Although the extent of these developments remains to be seen, estimates by MGI (2013) suggests that sophisticated algorithms could substitute for approximately 140 million full-time knowledge workers worldwide. Hence, while technological progress throughout economic history has largely been confined to the mechanisation of manual tasks, requiring physical labour, technological progress in the twenty-first century can be expected to contribute to a wide range of cognitive tasks, which, until now, have largely remained a human domain. Of course, many occupations being affected by these developments are still far from fully computerisable, meaning that the computerisation of some tasks will simply free-up time for human labour to perform other tasks. Nonetheless, the trend is clear: computers increasingly challenge human labour in a wide range of cognitive tasks (Brynjolfsson and McAfee, 2011). 


\section{III.B. Computerisation in non-routine manual tasks}

Mobile robotics provides a means of directly leveraging ML technologies to aid the computerisation of a growing scope of manual tasks. The continued technological development of robotic hardware is having notable impact upon employment: over the past decades, industrial robots have taken on the routine tasks of most operatives in manufacturing. Now, however, more advanced robots are gaining enhanced sensors and manipulators, allowing them to perform non-routine manual tasks. For example, General Electric has recently developed robots to climb and maintain wind turbines, and more flexible surgical robots with a greater range of motion will soon perform more types of operations (Robotics-VO, 2013). In a similar manner, the computerisation of logistics is being aided by the increasing cost-effectiveness of highly instrumented and computerised cars. Mass-production vehicles, such as the Nissan LEAF, contain on-board computers and advanced telecommunication equipment that render the car a potentially fly-by-wire robot. ${ }^{17}$ Advances in sensor technology mean that vehicles are likely to soon be augmented with even more advanced suites of sensors. These will permit an algorithmic vehicle controller to monitor its environment to a degree that exceeds the capabilities of any human driver: they have the ability to simultaneously look both forwards and backwards, can natively integrate camera, GPS and LIDAR data, and are not subject to distraction. Algorithms are thus potentially safer and more effective drivers than humans.

The big data provided by these improved sensors are offering solutions to many of the engineering problems that had hindered robotic development in the past. In particular, the creation of detailed three dimensional maps of road networks has enabled autonomous vehicle navigation; most notably illustrated by Google's use of large, specialised datasets collected by its driverless cars (Guizzo, 2011). It is now completely feasible to store representations of the entire road network on-board a car, dramatically simplifying the navigation problem. Algorithms that could perform navigation throughout the changing seasons, particularly after snowfall, have been viewed as a substantial challenge. However, the big data approach can answer this by storing records from the last time snow fell, against which the vehicle's current environment can be compared (Churchill and Newman, 2012). ML approaches have also been

\footnotetext{
${ }^{17} \mathrm{~A}$ fly-by-wire robot is a robot that is controllable by a remote computer.
} 
developed to identify unprecedented changes to a particular piece of the road network, such as roadworks (Mathibela, et al., 2012). This emerging technology will affect a variety of logistics jobs. Agricultural vehicles, forklifts and cargo-handling vehicles are imminently automatable, and hospitals are already employing autonomous robots to transport food, prescriptions and samples (Bloss, 2011). The computerisation of mining vehicles is further being pursued by companies such as Rio Tinto, seeking to replace labour in Australian mine-sites. ${ }^{18}$

With improved sensors, robots are capable of producing goods with higher quality and reliability than human labour. For example, El Dulze, a Spanish food processor, now uses robotics to pick up heads of lettuce from a conveyor belt, rejecting heads that do not comply with company standards. This is achieved by measuring their density and replacing them on the belt (IFR, 2012a). Advanced sensors further allow robots to recognise patterns. Baxter, a 22,000 USD general-purpose robot, provides a well-known example. The robot features an LCD display screen displaying a pair of eyes that take on different expressions depending on the situation. When the robot is first installed or needs to learn a new pattern, no programming is required. A human worker simply guides the robot arms through the motions that will be needed for the task. Baxter then memorises these patterns and can communicate that it has understood its new instructions. While the physical flexibility of Baxter is limited to performing simple operations such as picking up objects and moving them, different standard attachments can be installed on its arms, allowing Baxter to perform a relatively broad scope of manual tasks at low cost (MGI, 2013).

Technological advances are contributing to declining costs in robotics. Over the past decades, robot prices have fallen about 10 percent annually and are expected to decline at an even faster pace in the near future (MGI, 2013). Industrial robots, with features enabled by machine vision and high-precision dexterity, which typically cost 100,000 to 150,000 USD, will be available for 50,000 to 75,000 USD in the next decade, with higher levels of intelligence and additional capabilities (IFR, 2012b). Declining robot prices will inevitably place them within reach of more users. For example, in China, employers are increasingly incentivised to substitute robots for labour, as wages and living standards

\footnotetext{
${ }^{18}$ Rio Tinto's computerisation efforts are advertised at http://www.mineofthefuture.com.au.
} 
are rising - Foxconn, a Chinese contract manufacturer that employs 1.2 million workers, is now investing in robots to assemble products such as the Apple iPhone (Markoff, 2012). According to the International Federation of Robotics, robot sales in China grew by more than 50 percent in 2011 and are expected to increase further. Globally, industrial robot sales reached a record 166,000 units in 2011, a 40 percent year-on-year increase (IFR, 2012b). Most likely, there will be even faster growth ahead as low-priced general-purpose models, such as Baxter, are adopted in simple manufacturing and service work.

Expanding technological capabilities and declining costs will make entirely new uses for robots possible. Robots will likely continue to take on an increasing set of manual tasks in manufacturing, packing, construction, maintenance, and agriculture. In addition, robots are already performing many simple service tasks such as vacuuming, mopping, lawn mowing, and gutter cleaning the market for personal and household service robots is growing by about 20 percent annually (MGI, 2013). Meanwhile, commercial service robots are now able to perform more complex tasks in food preparation, health care, commercial cleaning, and elderly care (Robotics-VO, 2013). As robot costs decline and technological capabilities expand, robots can thus be expected to gradually substitute for labour in a wide range of low-wage service occupations, where most Us job growth has occurred over the past decades (Autor and Dorn, 2013). This means that many low-wage manual jobs that have been previously protected from computerisation could diminish over time.

\section{III.C. The task model revisited}

The task model of Autor, et al. (2003) has delivered intuitive and accurate predictions in that: (a) computers are more substitutable for human labour in routine relative to non-routine tasks; and (b) a greater intensity of routine inputs increases the marginal productivity of non-routine inputs. Accordingly, computers have served as a substitute for labour for many routine tasks, while exhibiting strong complementarities with labour performing cognitive non-routine tasks. ${ }^{19}$ Yet the premises about what computers do have recently expanded. Computer capital can now equally substitute for a wide range of tasks commonly defined as non-routine (Brynjolfsson and McAfee, 2011), meaning that

\footnotetext{
${ }^{19}$ The model does not predict any substantial substitution or complementarity with nonroutine manual tasks.
} 
the task model will not hold in predicting the impact of computerisation on the task content of employment in the twenty-first century. While focusing on the substitution effects of recent technological progress, we build on the task model by deriving several factors that we expect will determine the extent of computerisation in non-routine tasks.

The task model assumes for tractability an aggregate, constant-returns-toscale Cobb-Douglas production function of the form,

$$
Q=\left(L_{\mathrm{S}}+C\right)^{1-\beta} L_{\mathrm{NS}}^{\beta}, \quad \beta \in[0,1]
$$

where $L_{\mathrm{S}}$ and $L_{\mathrm{NS}}$ are susceptible and non-susceptible labor inputs and $C$ is computer capital. Computer capital is supplied perfectly elastically at market price per efficiency unit, where the market price is falling exogenously with time due to technological progress. It further assumes income-maximizing workers, with heterogeneous productivity endowments in both susceptible and non-susceptible tasks. Their task supply will respond elastically to relative wage levels, meaning that workers will reallocate their labour supply according to their comparative advantage as in Roy (1951). With expanding computational capabilities, resulting from technological advances, and a falling market price of computing, workers in susceptible tasks will thus reallocate to nonsusceptible tasks.

The above described simple model differs from the task model of Autor, et al. (2003), in that $L_{\mathrm{NS}}$ is not confined to routine labour inputs. This is because recent developments in ML and MR, building upon big data, allow for pattern recognition, and thus enable computer capital to rapidly substitute for labour across a wide range of non-routine tasks. Yet some inhibiting engineering bottlenecks to computerisation persist. Beyond these bottlenecks, however, we argue that it is largely already technologically possible to automate almost any task, provided that sufficient amounts of data are gathered for pattern recognition. Our model thus predicts that the pace at which these bottlenecks can be overcome will determine the extent of computerisation in the twenty-first century.

Hence, in short, while the task model predicts that computers for labour substitution will be confined to routine tasks, our model predicts that comput- 
erisation can be extended to any non-routine task that is not subject to any engineering bottlenecks to computerisation. These bottlenecks thus set the boundaries for the computerisation of non-routine tasks. Drawing upon the ML and MR literature, and a workshop held at the Oxford University Engineering Sciences Department, we identify several engineering bottlenecks, corresponding to three task categories. According to these findings, non-susceptible labor inputs can be described as,

$$
L_{\mathrm{NS}}=\sum_{i=1}^{n}\left(L_{\mathrm{PM}, i}+L_{\mathrm{C}, i}+L_{\mathrm{SI}, i}\right)
$$

where $L_{\mathrm{PM}}, L_{\mathrm{C}}$ and $L_{\mathrm{SI}}$ are labour inputs into perception and manipulation tasks, creative intelligence tasks, and and social intelligence tasks.

We note that some related engineering bottlenecks can be partially alleviated by the simplification of tasks. One generic way of achieving this is to reduce the variation between task iterations. As a prototypical example, consider the factory assembly line, turning the non-routine tasks of the artisan shop into repetitive routine tasks performed by unskilled factory workers. A more recent example is the computerisation of non-routine manual tasks in construction. On-site construction tasks typically demand a high degree of adaptability, so as to accommodate work environments that are typically irregularly laid out, and vary according to weather. Prefabrication, in which the construction object is partially assembled in a factory before being transported to the construction site, provides a way of largely removing the requirement for adaptability. It allows many construction tasks to be performed by robots under controlled conditions that eliminate task variability - a method that is becoming increasingly widespread, particularly in Japan (Barlow and Ozaki, 2005; Linner and Bock, 2012). The extent of computerisation in the twenty-first century will thus partly depend on innovative approaches to task restructuring. In the remainder of this section we examine the engineering bottlenecks related to the above mentioned task categories, each in turn.

Perception and manipulation tasks. Robots are still unable to match the depth and breadth of human perception. While basic geometric identification is reasonably mature, enabled by the rapid development of sophisticated sensors 
and lasers, significant challenges remain for more complex perception tasks, such as identifying objects and their properties in a cluttered field of view. As such, tasks that relate to an unstructured work environment can make jobs less susceptible to computerisation. For example, most homes are unstructured, requiring the identification of a plurality of irregular objects and containing many cluttered spaces which inhibit the mobility of wheeled objects. Conversely, supermarkets, factories, warehouses, airports and hospitals have been designed for large wheeled objects, making it easier for robots to navigate in performing non-routine manual tasks. Perception problems can, however, sometimes be sidestepped by clever task design. For example, Kiva Systems, acquired by Amazon.com in 2012, solved the problem of warehouse navigation by simply placing bar-code stickers on the floor, informing robots of their precise location (Guizzo, 2008).

The difficulty of perception has ramifications for manipulation tasks, and, in particular, the handling of irregular objects, for which robots are yet to reach human levels of aptitude. This has been evidenced in the development of robots that interact with human objects and environments. While advances have been made, solutions tend to be unreliable over the myriad small variations on a single task, repeated thousands of times a day, that many applications require. A related challenge is failure recovery - i.e. identifying and rectifying the mistakes of the robot when it has, for example, dropped an object. Manipulation is also limited by the difficulties of planning out the sequence of actions required to move an object from one place to another. There are yet further problems in designing manipulators that, like human limbs, are soft, have compliant dynamics and provide useful tactile feedback. Most industrial manipulation makes uses of workarounds to these challenges (Brown, et al., 2010), but these approaches are nonetheless limited to a narrow range of tasks. The main challenges to robotic computerisation, perception and manipulation, thus largely remain and are unlikely to be fully resolved in the next decade or two (Robotics-VO, 2013).

Creative intelligence tasks. The psychological processes underlying human creativity are difficult to specify. According to Boden (2003), creativity is the ability to come up with ideas or artifacts that are novel and valuable. Ideas, in a broader sense, include concepts, poems, musical compositions, scientific theo- 
ries, cooking recipes and jokes, whereas artifacts are objects such as paintings, sculptures, machinery, and pottery. One process of creating ideas (and similarly for artifacts) involves making unfamiliar combinations of familiar ideas, requiring a rich store of knowledge. The challenge here is to find some reliable means of arriving at combinations that "make sense." For a computer to make a subtle joke, for example, would require a database with a richness of knowledge comparable to that of humans, and methods of benchmarking the algorithm's subtlety.

In principle, such creativity is possible and some approaches to creativity already exist in the literature. Duvenaud, et al. (2013) provide an example of automating the core creative task required in order to perform statistics, that of designing models for data. As to artistic creativity, AARON, a drawingprogram, has generated thousands of stylistically-similar line-drawings, which have been exhibited in galleries worldwide. Furthermore, David Cope's EMI software composes music in many different styles, reminiscent of specific human composers.

In these and many other applications, generating novelty is not particularly difficult. Instead, the principal obstacle to computerising creativity is stating our creative values sufficiently clearly that they can be encoded in an program (Boden, 2003). Moreover, human values change over time and vary across cultures. Because creativity, by definition, involves not only novelty but value, and because values are highly variable, it follows that many arguments about creativity are rooted in disagreements about value. Thus, even if we could identify and encode our creative values, to enable the computer to inform and monitor its own activities accordingly, there would still be disagreement about whether the computer appeared to be creative. In the absence of engineering solutions to overcome this problem, it seems unlikely that occupations requiring a high degree of creative intelligence will be automated in the next decades.

Social intelligence tasks. Human social intelligence is important in a wide range of work tasks, such as those involving negotiation, persuasion and care. To aid the computerisation of such tasks, active research is being undertaken within the fields of Affective Computing (Scherer, et al., 2010; Picard, 2010), and Social Robotics (Ge, 2007; Broekens, et al., 2009). While algorithms and robots can now reproduce some aspects of human social interaction, the real- 
time recognition of natural human emotion remains a challenging problem, and the ability to respond intelligently to such inputs is even more difficult. Even simplified versions of typical social tasks prove difficult for computers, as is the case in which social interaction is reduced to pure text. The social intelligence of algorithms is partly captured by the Turing test, examining the ability of a machine to communicate indistinguishably from an actual human. Since 1990, the Loebner Prize, an annual Turing test competition, awards prizes to textual chat programmes that are considered to be the most human-like. In each competition, a human judge simultaneously holds computer-based textual interactions with both an algorithm and a human. Based on the responses, the judge is to distinguish between the two. Sophisticated algorithms have so far failed to convince judges about their human resemblance. This is largely because there is much 'common sense' information possessed by humans, which is difficult to articulate, that would need to be provided to algorithms if they are to function in human social settings.

Whole brain emulation, the scanning, mapping and digitalising of a human brain, is one possible approach to achieving this, but is currently only a theoretical technology. For brain emulation to become operational, additional functional understanding is required to recognise what data is relevant, as well as a roadmap of technologies needed to implement it. While such roadmaps exist, present implementation estimates, under certain assumptions, suggest that whole brain emulation is unlikely to become operational within the next decade or two (Sandberg and Bostrom, 2008). When or if they do, however, the employment impact is likely to be vast (Hanson, 2001).

Hence, in short, while sophisticated algorithms and developments in MR, building upon with big data, now allow many non-routine tasks to be automated, occupations that involve complex perception and manipulation tasks, creative intelligence tasks, and social intelligence tasks are unlikely to be substituted by computer capital over the next decade or two. The probability of an occupation being automated can thus be described as a function of these task characteristics. As suggested by Figure I, the low degree of social intelligence required by a dishwasher makes this occupation more susceptible to computerisation than a public relation specialist, for example. We proceed to examining the susceptibility of jobs to computerisation as a function of the above described non-susceptible task characteristics. 


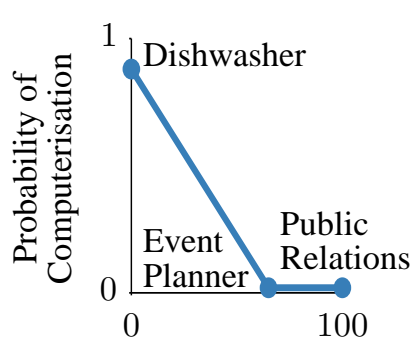

Social Intelligence
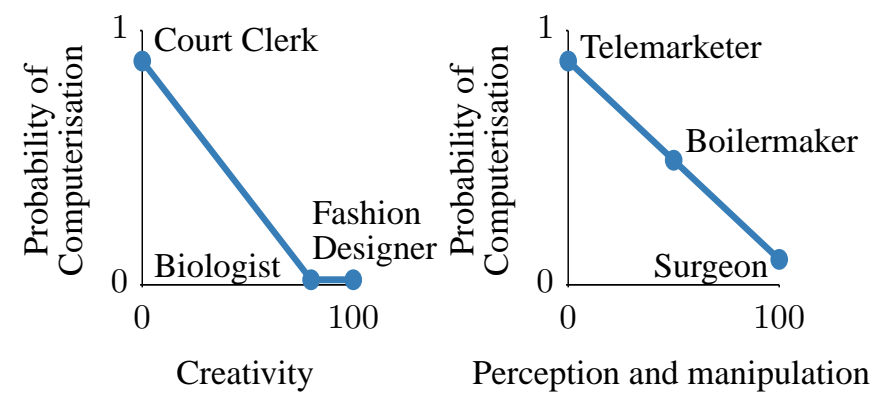

FIGURE I. A sketch of how the probability of computerisation might vary as a function of bottleneck variables.

\section{MEASURING THE EMPLOYMENT IMPACT OF COMPUTERISATION}

\section{IV.A. Data sources and implementation strategy}

To implement the above described methodology, we rely on $\mathrm{O} * \mathrm{NET}$, an online service developed for the US Department of Labor. The 2010 version of $\mathrm{O} *$ NET contains information on 903 detailed occupations, most of which correspond closely to the Labor Department's Standard Occupational Classification (SOC). The $\mathrm{O} *$ NET data was initially collected from labour market analysts, and has since been regularly updated by surveys of each occupation's worker population and related experts, to provide up-to-date information on occupations as they evolve over time. For our purposes, an important feature of $\mathrm{O} * \mathrm{NET}$ is that it defines the key features of an occupation as a standardised and measurable set of variables, but also provides open-ended descriptions of specific tasks to each occupation. This allows us to: (a) objectively rank occupations according to the mix of knowledge, skills, and abilities they require; and (b) subjectively categorise them based on the variety of tasks they involve.

The close SOC correspondence of $\mathrm{O} * \mathrm{NET}$ allows us to link occupational characteristics to 2010 Bureau of Labor Statistics (BLS) employment and wage data. While the $\mathrm{O} *$ NET occupational classification is somewhat more detailed, distinguishing between Auditors and Accountants, for example, we aggregate these occupations to correspond to the six-digit 2010 SOC system, for which employment and wage figures are reported. To obtain unique $\mathrm{O} * \mathrm{NET}$ variables corresponding to the six-digit soc classification, we used the mean of the $\mathrm{O} * \mathrm{NET}$ aggregate. In addition, we exclude any six-digit SOC occupations 
for which $\mathrm{O} *$ NET data was missing. ${ }^{20}$ Doing so, we end up with a final dataset consisting of 702 occupations.

To assess the employment impact of the described technological developments in ML, the ideal experiment would provide two identical autarkic economies, one facing the expanding technological capabilities we observe, and a secular decline in the price of computerisation, and the other not. By comparison, it would be straightforward to examine how computerisation reshapes the occupational composition of the labour market. In the absence of this experiment, the second preferred option would be to build on the implementation strategy of Autor, et al. (2003), and test a simple economic model to predict how demand for workplace tasks responds to developments in ML and MR technology. However, because our paper is forward-looking, in the sense that most of the described technological developments are yet to be implemented across industries on a broader scale, this option was not available for our purposes.

Instead, our implementation strategy builds on the literature examining the offshoring of information-based tasks to foreign worksites, consisting of different methodologies to rank and categorise occupations according to their susceptibility to offshoring (Blinder, 2009; Jensen and Kletzer, 2005, 2010). The common denominator for these studies is that they rely on $\mathrm{O} *$ NET data in different ways. While Blinder (2009) eyeballed the $\mathrm{O} * \mathrm{NET}$ data on each occupation, paying particular attention to the job description, tasks, and work activities, to assign an admittedly subjective two-digit index number of offshorability to each occupation, Jensen and Kletzer (2005) created a purely objective ranking based on standardised and measurable $\mathrm{O} *$ NET variables. Both approaches have obvious drawbacks. Subjective judgments are often not replicable and may result in the researcher subconsciously rigging the data to conform to a certain set of beliefs. Objective rankings, on the other hand, are not subject to such drawbacks, but are constrained by the reliability of the variables that are being used. At this stage, it shall be noted that $\mathrm{O} *$ NET data was not gathered to specifically measure the offshorability or automatability of jobs. Accordingly, Blinder (2009)

\footnotetext{
${ }^{20}$ The missing occupations consist of "All Other" titles, representing occupations with a wide range of characteristics which do not fit into one of the detailed O*NET-SOC occupations. $\mathrm{O} *$ NET data is not available for this type of title. We note that US employment for the 702 occupations we considered is 138.44 million. Hence our analysis excluded 4.628 million jobs, equivalent to 3 percent of total employment.
} 
finds that past attempts to create objective offshorability rankings using $\mathrm{O} * \mathrm{NET}$ data have yielded some questionable results, ranking lawyers and judges among the most tradable occupations, while classifying occupations such as data entry keyers, telephone operators, and billing clerks as virtually impossible to move offshore.

To work around some of these drawbacks, we combine and build upon the two described approaches. First, together with a group of ML researchers, we subjectively hand-labelled 70 occupations, assigning 1 if automatable, and 0 if not. For our subjective assessments, we draw upon a workshop held at the Oxford University Engineering Sciences Department, examining the automatability of a wide range of tasks. Our label assignments were based on eyeballing the $\mathrm{O} * \mathrm{NET}$ tasks and job description of each occupation. This information is particular to each occupation, as opposed to standardised across different jobs. The hand-labelling of the occupations was made by answering the question "Can the tasks of this job be sufficiently specified, conditional on the availability of big data, to be performed by state of the art computer-controlled equipment". Thus, we only assigned a 1 to fully automatable occupations, where we considered all tasks to be automatable. To the best of our knowledge, we considered the possibility of task simplification, possibly allowing some currently non-automatable tasks to be automated. Labels were assigned only to the occupations about which we were most confident.

Second, we use objective $\mathrm{O} * \mathrm{NET}$ variables corresponding to the defined bottlenecks to computerisation. More specifically, we are interested in variables describing the level of perception and manipulation, creativity, and social intelligence required to perform it. As reported in Table I, we identified nine variables that describe these attributes. These variables were derived from the $\mathrm{O} *$ NET survey, where the respondents are given multiple scales, with "importance" and "level" as the predominant pair. We rely on the "level" rating which corresponds to specific examples about the capabilities required of computercontrolled equipment to perform the tasks of an occupation. For instance, in relation to the attribute "Manual Dexterity", low (level) corresponds to "Screw a light bulb into a light socket"; medium (level) is exemplified by "Pack oranges in crates as quickly as possible"; high (level) is described as "Perform open-heart surgery with surgical instruments". This gives us an indication of the level of "Manual Dexterity" computer-controlled equipment would require 
TABLE I. O*NET variables that serve as indicators of bottlenecks to computerisation.

\begin{tabular}{|c|c|c|}
\hline $\begin{array}{l}\text { Computerisation } \\
\text { bottleneck }\end{array}$ & $\mathrm{O} *$ NET Variable & $\mathrm{O} *$ NET Description \\
\hline \multirow[t]{3}{*}{$\begin{array}{l}\text { Perception } \\
\text { and } \\
\text { Manipulation }\end{array}$} & $\begin{array}{l}\text { Finger } \\
\text { Dexterity }\end{array}$ & $\begin{array}{l}\text { The ability to make precisely coordinated movements of } \\
\text { the fingers of one or both hands to grasp, manipulate, or } \\
\text { assemble very small objects. }\end{array}$ \\
\hline & $\begin{array}{l}\text { Manual } \\
\text { Dexterity }\end{array}$ & $\begin{array}{l}\text { The ability to quickly move your hand, your hand together } \\
\text { with your arm, or your two hands to grasp, manipulate, or } \\
\text { assemble objects. }\end{array}$ \\
\hline & $\begin{array}{l}\text { Cramped Work Space, } \\
\text { Awkward Positions }\end{array}$ & $\begin{array}{l}\text { How often does this job require working in cramped work } \\
\text { spaces that requires getting into awkward positions? }\end{array}$ \\
\hline \multirow[t]{2}{*}{$\begin{array}{l}\text { Creative } \\
\text { Intelligence }\end{array}$} & Originality & $\begin{array}{l}\text { The ability to come up with unusual or clever ideas about } \\
\text { a given topic or situation, or to develop creative ways to } \\
\text { solve a problem. }\end{array}$ \\
\hline & Fine Arts & $\begin{array}{l}\text { Knowledge of theory and techniques required to compose, } \\
\text { produce, and perform works of music, dance, visual arts, } \\
\text { drama, and sculpture. }\end{array}$ \\
\hline \multirow[t]{4}{*}{$\begin{array}{l}\text { Social } \\
\text { Intelligence }\end{array}$} & $\begin{array}{l}\text { Social } \\
\text { Perceptiveness }\end{array}$ & $\begin{array}{l}\text { Being aware of others' reactions and understanding why } \\
\text { they react as they do. }\end{array}$ \\
\hline & Negotiation & $\begin{array}{l}\text { Bringing others together and trying to reconcile } \\
\text { differences. }\end{array}$ \\
\hline & Persuasion & Persuading others to change their minds or behavior. \\
\hline & $\begin{array}{l}\text { Assisting and Caring for } \\
\text { Others }\end{array}$ & $\begin{array}{l}\text { Providing personal assistance, medical attention, emo- } \\
\text { tional support, or other personal care to others such as } \\
\text { coworkers, customers, or patients. }\end{array}$ \\
\hline
\end{tabular}

to perform a specific occupation. An exception is the "Cramped work space" variable, which measures the frequency of unstructured work.

Hence, in short, by hand-labelling occupations, we work around the issue that $\mathrm{O} * \mathrm{NET}$ data was not gathered to specifically measure the automatability of jobs in a similar manner to Blinder (2009). In addition, we mitigate some of the subjective biases held by the researchers by using objective $\mathrm{O} * \mathrm{NET}$ variables to correct potential hand-labelling errors. The fact that we label only 70 of the full 702 occupations, selecting those occupations whose computerisation label we are highly confident about, further reduces the risk of subjective bias affecting our analysis. To develop an algorithm appropriate for this task, we turn to probabilistic classification. 


\section{IV.B. Classification method}

We begin by examining the accuracy of our subjective assessments of the automatability of 702 occupations. For classification, we develop an algorithm to provide the label probability given a previously unseen vector of variables. In the terminology of classification, the $\mathrm{O} * \mathrm{NET}$ variables form a feature vector, denoted $\underline{x} \in \mathbb{R}^{9}$. O $*$ NET hence supplies a complete dataset of 702 such feature vectors. A computerisable label is termed a class, denoted $y \in\{0,1\}$. For our problem, $y=1$ (true) implies that we hand-labelled as computerisable the occupation described by the associated nine $\mathrm{O} * \mathrm{NET}$ variables contained in $\underline{x} \in \mathbb{R}^{9}$. Our training data is $\mathcal{D}=(X, \underline{y})$, where $X \in \mathbb{R}^{70 \times 9}$ is a matrix of variables and $y \in\{0,1\}^{70}$ gives the associated labels. This dataset contains information about how $y$ varies as a function of $\underline{x}$ : as a hypothetical example, it may be the case that, for all occupations for which $x_{1}>50, y=1$. A probabilistic classification algorithm exploits patterns existent in training data to return the probability $P\left(y_{*}=1 \mid \underline{x}_{*}, X, \underline{y}\right)$ of a new, unlabelled, test datum with features $\underline{x}_{*}$ having class label $y_{*}=1$.

We achieve probabilistic classification by introducing a latent function $f: \underline{x} \mapsto \mathbb{R}$, known as a discriminant function. Given the value of the discriminant $f_{*}$ at a test point $\underline{x}_{*}$, we assume that the probability for the class label is given by the logistic

$$
P\left(y_{*}=1 \mid f_{*}\right)=\frac{1}{1+\exp \left(-f_{*}\right)},
$$

and $P\left(y_{*}=0 \mid f_{*}\right)=1-P\left(y_{*}=1 \mid f_{*}\right)$. For $f_{*}>0, y_{*}=1$ is more probable than $y_{*}=0$. For our application, $f$ can be thought of as a continuousvalued 'automatability' variable: the higher its value, the higher the probability of computerisation.

We test three different models for the discriminant function, $f$, using the best performing for our further analysis. Firstly, logistic (or logit) regression, which adopts a linear model for $f, f(\underline{x})=\underline{w}^{\top} \underline{x}$, where the un-known weights $\underline{w}$ are often inferred by maximising their probability in light of the training data. This simple model necessarily implies a simple monotonic relationship between features and the probability of the class taking a particular value. Richer models are provided by Gaussian process classifiers (Rasmussen and 
Williams, 2006). Such classifiers model the latent function $f$ with a Gaussian process (GP): a non-parametric probability distribution over functions.

A GP is defined as a distribution over the functions $f: \mathcal{X} \rightarrow \mathbb{R}$ such that the distribution over the possible function values on any finite subset of $\mathcal{X}$ (such as $X)$ is multivariate Gaussian. For a function $f(\underline{x})$, the prior distribution over its values $f$ on a subset $\underline{x} \subset \mathcal{X}$ are completely specified by a covariance matrix $K$

$$
p(f \mid K)=\mathcal{N}(\underline{f} ; \underline{0}, K)=\frac{1}{\sqrt{\operatorname{det} 2 \pi K}} \exp \left(-\frac{1}{2} f^{\top} K^{-1} f\right) .
$$

The covariance matrix is generated by a covariance function $\kappa: \mathcal{X} \times \mathcal{X} \mapsto \mathbb{R}$; that is, $K=\kappa(X, X)$. The GP model is expressed by the choice of $\kappa$; we consider the exponentiated quadratic (squared exponential) and rational quadratic. Note that we have chosen a zero mean function, encoding the assumption that $P\left(y_{*}=1\right)=\frac{1}{2}$ sufficiently far from training data.

Given training data $\mathcal{D}$, we use the GP to make predictions about the function values $f_{*}$ at input $\underline{x}_{*}$. With this information, we have the predictive equations

$$
p\left(f_{*} \mid \underline{x}_{*}, \mathcal{D}\right)=\mathcal{N}\left(f_{*} ; m\left(f_{*} \mid \underline{x}_{*}, \mathcal{D}\right), V\left(f_{*} \mid \underline{x}_{*}, \mathcal{D}\right)\right)
$$

where

$$
\begin{aligned}
& m\left(f_{*} \mid \underline{x}_{*}, \mathcal{D}\right)=K\left(\underline{x}_{*}, X\right) K(X, X)^{-1} \underline{y} \\
& V\left(f_{*} \mid \underline{x}_{*}, \mathcal{D}\right)=K\left(\underline{x}_{*}, x_{*}\right)-K\left(\underline{x}_{*}, X\right) K(X, X)^{-1} K\left(X, \underline{x}_{*}\right) .
\end{aligned}
$$

Inferring the label posterior $p\left(y_{*} \mid \underline{x}_{*}, \mathcal{D}\right)$ is complicated by the non-Gaussian form of the logistic (3). In order to effect inference, we use the approximate Expectation Propagation algorithm (Minka, 2001).

We tested three Gaussian process classifiers using the GPML toolbox (Rasmussen and Nickisch, 2010) on our data, built around exponentiated quadratic, rational quadratic and linear covariances. Note that the latter is equivalent to logistic regression with a Gaussian prior taken on the weights $\underline{w}$. To validate these classifiers, we randomly selected a reduced training set of half the available data $\mathcal{D}$; the remaining data formed a test set. On this test set, we evaluated how closely the algorithm's classifications matched the hand labels according to two metrics (see e.g. Murphy (2012)): the area under the receiver operat- 
TABLE II. Performance of various classifiers; best performances in bold.

\begin{tabular}{lrr}
\hline classifier model & AUC & log-likelihood \\
\hline exponentiated quadratic & $\mathbf{0 . 8 9 4}$ & $\mathbf{- 1 6 3 . 3}$ \\
rational quadratic & 0.893 & -163.7 \\
linear (logit regression) & 0.827 & -205.0 \\
\hline
\end{tabular}

ing characteristic curve (AUC), which is equal to one for a perfect classifier, and one half for a completely random classifier, and the log-likelihood, which should ideally be high. This experiment was repeated for one hundred random selections of training set, and the average results tabulated in Table II. The exponentiated quadratic model returns (narrowly) the best performance of the three (clearly outperforming the linear model corresponding to logistic regression), and was hence selected for the remainder of our testing. Note that its AUC score of nearly 0.9 represents accurate classification: our algorithm successfully managed to reproduce our hand-labels specifying whether an occupation was computerisable. This means that our algorithm verified that our subjective judgements were systematically and consistently related to the $\mathrm{O} * \mathrm{NET}$ variables.

Having validated our approach, we proceed to use classification to predict the probability of computerisation for all 702 occupations. For this purpose, we introduce a new label variable, $z$, denoting whether an occupation is truly computerisable or not: note that this can be judged only once an occupation is computerised, at some indeterminate point in the future. We take, again, a logistic likelihood,

$$
P\left(z_{*}=1 \mid f_{*}\right)=\frac{1}{1+\exp \left(-f_{*}\right)} .
$$

We implicitly assumed that our hand label, $y$, is a noise-corrupted version of the unknown true label, $z$. Our motivation is that our hand-labels of computerisability must necessarily be treated as such noisy measurements. We thus acknowledge that it is by no means certain that a job is computerisable given our labelling. We define $X_{*} \in \mathbb{R}^{702 \times 9}$ as the matrix of $\mathrm{O} *$ NET variables for all 702 occupations; this matrix represents our test features.

We perform a final experiment in which, given training data $\mathcal{D}$, consisting 

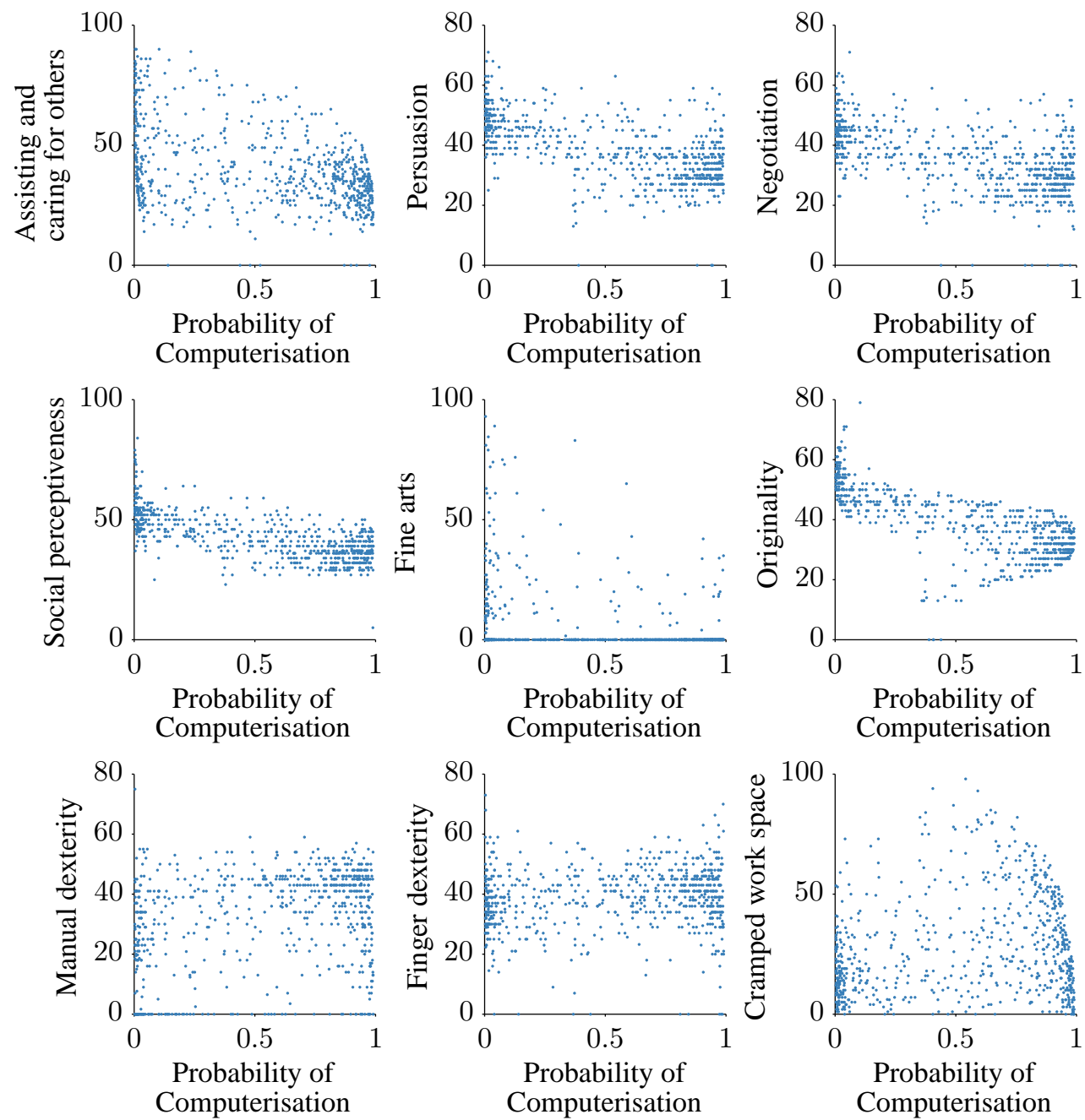

FIGURE II. The distribution of occupational variables as a function of probability of computerisation; each occupation is a unique point. 
of our 70 hand-labelled occupations, we aim to predict $\underline{z}_{*}$ for our test features $X_{*}$. This approach firstly allows us to use the features of the 70 occupations about which we are most certain to predict for the remaining 632. Further, our algorithm uses the trends and patterns it has learned from bulk data to correct for what are likely to be mistaken labels. More precisely, the algorithm provides a smoothly varying probabilistic assessment of automatability as a function of the variables. For our Gaussian process classifier, this function is non-linear, meaning that it flexibly adapts to the patterns inherent in the training data. Our approach thus allows for more complex, non-linear, interactions between variables: for example, perhaps one variable is not of importance unless the value of another variable is sufficiently large. We report $P\left(\underline{z}_{*} \mid X_{*}, \mathcal{D}\right)$ as the probability of computerisation henceforth (for a detailed probability ranking, see Appendix). Figure II illustrates that this probability is non-linearly related to the nine $\mathrm{O} * \mathrm{NET}$ variables selected.

\section{EMPLOYMENT IN THE TWENTY-FIRST CENTURY}

In this section, we examine the possible future extent of at-risk job computerisation, and related labour market outcomes. The task model predicts that recent developments in ML will reduce aggregate demand for labour input in tasks that can be routinised by means of pattern recognition, while increasing the demand for labour performing tasks that are not susceptible to computerisation. However, we make no attempt to forecast future changes in the occupational composition of the labour market. While the 2010-2020 BLS occupational employment projections predict US net employment growth across major occupations, based on historical staffing patterns, we speculate about technology that is in only the early stages of development. This means that historical data on the impact of the technological developments we observe is unavailable. ${ }^{21} \mathrm{We}$ therefore focus on the impact of computerisation on the mix of jobs that existed in 2010. Our analysis is thus limited to the substitution effect of future computerisation.

Turning first to the expected employment impact, reported in Figure III, we distinguish between high, medium and low risk occupations, depending on their

\footnotetext{
${ }^{21}$ It shall be noted that the BLS projections are based on what can be referred to as changes in normal technological progress, and not on any breakthrough technologies that may be seen as conjectural.
} 


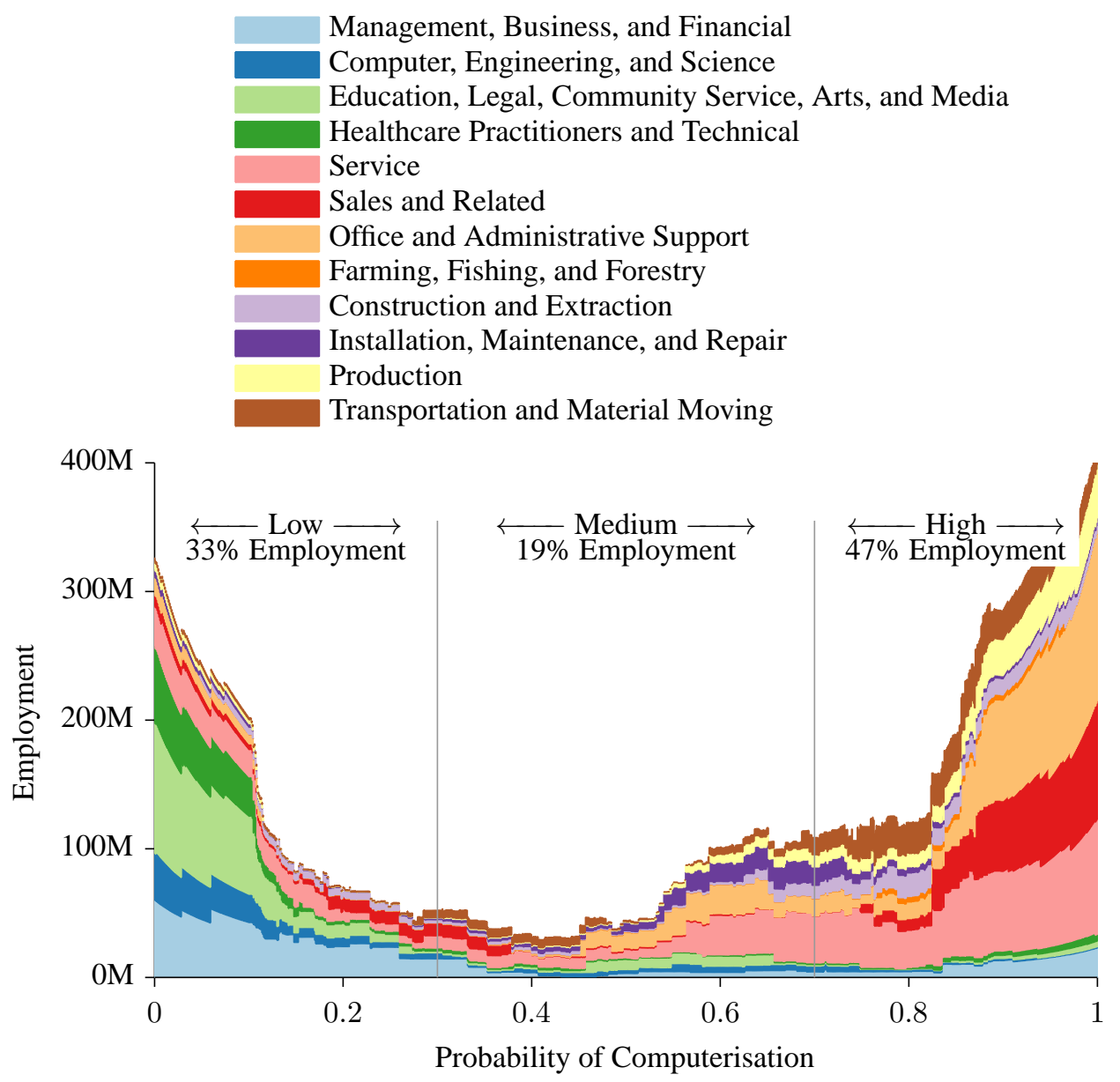

FIGURE III. The distribution of BLS 2010 occupational employment over the probability of computerisation, along with the share in low, medium and high probability categories. Note that the total area under all curves is equal to total US employment. 
probability of computerisation (thresholding at probabilities of 0.7 and 0.3 ). According to our estimate, 47 percent of total Us employment is in the high risk category, meaning that associated occupations are potentially automatable over some unspecified number of years, perhaps a decade or two. It shall be noted that the probability axis can be seen as a rough timeline, where high probability occupations are likely to be substituted by computer capital relatively soon. Over the next decades, the extent of computerisation will be determined by the pace at which the above described engineering bottlenecks to automation can be overcome. Seen from this perspective, our findings could be interpreted as two waves of computerisation, separated by a "technological plateau". In the first wave, we find that most workers in transportation and logistics occupations, together with the bulk of office and administrative support workers, and labour in production occupations, are likely to be substituted by computer capital. As computerised cars are already being developed and the declining cost of sensors makes augmenting vehicles with advanced sensors increasingly cost-effective, the automation of transportation and logistics occupations is in line with the technological developments documented in the literature. Furthermore, algorithms for big data are already rapidly entering domains reliant upon storing or accessing information, making it equally intuitive that office and administrative support occupations will be subject to computerisation. The computerisation of production occupations simply suggests a continuation of a trend that has been observed over the past decades, with industrial robots taking on the routine tasks of most operatives in manufacturing. As industrial robots are becoming more advanced, with enhanced senses and dexterity, they will be able to perform a wider scope of non-routine manual tasks. From a technological capabilities point of view, the vast remainder of employment in production occupations is thus likely to diminish over the next decades.

More surprising, at first sight, is that a substantial share of employment in services, sales and construction occupations exhibit high probabilities of computerisation. Yet these findings are largely in line with recent documented technological developments. First, the market for personal and household service robots is already growing by about 20 percent annually (MGI, 2013). As the comparative advantage of human labour in tasks involving mobility and dexterity will diminish over time, the pace of labour substitution in service occupations is likely to increase even further. Second, while it seems counterintuitive 
that sales occupations, which are likely to require a high degree of social intelligence, will be subject to a wave of computerisation in the near future, high risk sales occupations include, for example, cashiers, counter and rental clerks, and telemarketers. Although these occupations involve interactive tasks, they do not necessarily require a high degree of social intelligence. Our model thus seems to do well in distinguishing between individual occupations within occupational categories. Third, prefabrication will allow a growing share of construction work to be performed under controlled conditions in factories, which partly eliminates task variability. This trend is likely to drive the computerisation of construction work.

In short, our findings suggest that recent developments in ML will put a substantial share of employment, across a wide range of occupations, at risk in the near future. According to our estimates, however, this wave of automation will be followed by a subsequent slowdown in computers for labour substitution, due to persisting inhibiting engineering bottlenecks to computerisation. The relatively slow pace of computerisation across the medium risk category of employment can thus partly be interpreted as a technological plateau, with incremental technological improvements successively enabling further labour substitution. More specifically, the computerisation of occupations in the medium risk category will mainly depend on perception and manipulation challenges. This is evident from Table III, showing that the "manual dexterity", "finger dexterity" and "cramped work space" variables exhibit relatively high values in the medium risk category. Indeed, even with recent technological developments, allowing for more sophisticated pattern recognition, human labour will still have a comparative advantage in tasks requiring more complex perception and manipulation. Yet with incremental technological improvements, the comparative advantage of human labour in perception and manipulation tasks could eventually diminish. This will require innovative task restructuring, improvements in ML approaches to perception challenges, and progress in robotic dexterity to overcome manipulation problems related to variation between task iterations and the handling of irregular objects. The gradual computerisation of installation, maintenance, and repair occupations, which are largely confined to the medium risk category, and require a high degree of perception and manipulation capabilities, is a manifestation of this observation.

Our model predicts that the second wave of computerisation will mainly 
TABLE III. Distribution (mean and standard deviation) of values for each variable.

\begin{tabular}{lccc}
\hline Variable & \multicolumn{3}{c}{ Probability of Computerisation } \\
\cline { 2 - 4 } & Low & Medium & High \\
\hline Assisting and caring for others & $48 \pm 20$ & $41 \pm 17$ & $34 \pm 10$ \\
Persuasion & $48 \pm 7.1$ & $35 \pm 9.8$ & $32 \pm 7.8$ \\
Negotiation & $44 \pm 7.6$ & $33 \pm 9.3$ & $30 \pm 8.9$ \\
Social perceptiveness & $51 \pm 7.9$ & $41 \pm 7.4$ & $37 \pm 5.5$ \\
Fine arts & $12 \pm 20$ & $3.5 \pm 12$ & $1.3 \pm 5.5$ \\
Originality & $51 \pm 6.5$ & $35 \pm 12$ & $32 \pm 5.6$ \\
Manual dexterity & $22 \pm 18$ & $34 \pm 15$ & $36 \pm 14$ \\
Finger dexterity & $36 \pm 10$ & $39 \pm 10$ & $40 \pm 10$ \\
Cramped work space & $19 \pm 15$ & $37 \pm 26$ & $31 \pm 20$ \\
\hline
\end{tabular}

depend on overcoming the engineering bottlenecks related to creative and social intelligence. As reported in Table III, the "fine arts", "originality", "negotiation", "persuasion", "social perceptiveness", and "assisting and caring for others", variables, all exhibit relatively high values in the low risk category. By contrast, we note that the "manual dexterity", "finger dexterity" and "cramped work space" variables take relatively low values. Hence, in short, generalist occupations requiring knowledge of human heuristics, and specialist occupations involving the development of novel ideas and artifacts, are the least susceptible to computerisation. As a prototypical example of generalist work requiring a high degree of social intelligence, consider the $\mathrm{O} *$ NET tasks reported for chief executives, involving "conferring with board members, organization officials, or staff members to discuss issues, coordinate activities, or resolve problems", and "negotiating or approving contracts or agreements." Our predictions are thus intuitive in that most management, business, and finance occupations, which are intensive in generalist tasks requiring social intelligence, are largely confined to the low risk category. The same is true of most occupations in education, healthcare, as well as arts and media jobs. The O*NET tasks of actors, for example, involve "performing humorous and serious interpretations of emotions, actions, and situations, using body movements, facial expressions, and gestures", and "learning about characters in scripts and their relationships to each other in order to develop role interpretations." While these tasks are 

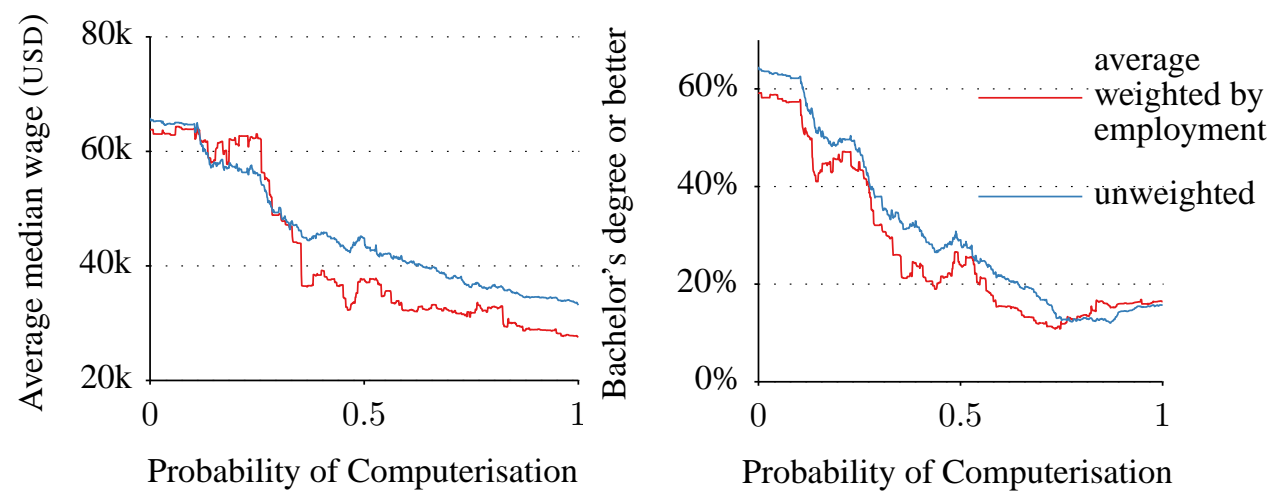

FIGURE IV. Wage and education level as a function of the probability of computerisation; note that both plots share a legend.

very different from those of a chief executive, they equally require profound knowledge of human heuristics, implying that a wide range of tasks, involving social intelligence, are unlikely to become subject to computerisation in the near future.

The low susceptibility of engineering and science occupations to computerisation, on the other hand, is largely due to the high degree of creative intelligence they require. The $\mathrm{O} * \mathrm{NET}$ tasks of mathematicians, for example, involve "developing new principles and new relationships between existing mathematical principles to advance mathematical science" and "conducting research to extend mathematical knowledge in traditional areas, such as algebra, geometry, probability, and logic." Hence, while it is evident that computers are entering the domains of science and engineering, our predictions implicitly suggest strong complementarities between computers and labour in creative science and engineering occupations; although it is possible that computers will fully substitute for workers in these occupations over the long-run. We note that the predictions of our model are strikingly in line with the technological trends we observe in the automation of knowledge work, even within occupational categories. For example, we find that paralegals and legal assistants - for which computers already substitute - in the high risk category. At the same time, lawyers, which rely on labour input from legal assistants, are in the low risk category. Thus, for the work of lawyers to be fully automated, engineering bottlenecks to creative and social intelligence will need to be overcome, implying that the computerisation of legal research will complement the work of lawyers in the medium term. 
To complete the picture of what recent technological progress is likely to mean for the future of employment, we plot the average median wage of occupations by their probability of computerisation. We do the same for skill level, measured by the fraction of workers having obtained a bachelor's degree, or higher educational attainment, within each occupation. Figure IV reveals that both wages and educational attainment exhibit a strong negative relationship with the probability of computerisation. We note that this prediction implies a truncation in the current trend towards labour market polarization, with growing employment in high and low-wage occupations, accompanied by a hollowing-out of middle-income jobs. Rather than reducing the demand for middle-income occupations, which has been the pattern over the past decades, our model predicts that computerisation will mainly substitute for low-skill and low-wage jobs in the near future. By contrast, high-skill and high-wage occupations are the least susceptible to computer capital.

Our findings were robust to the choice of the 70 occupations that formed our training data. This was confirmed by the experimental results tabulated in Table II: a GP classifier trained on half of the training data was demonstrably able to accurately predict the labels of the other half, over one hundred different partitions. That these predictions are accurate for many possible partitions of the training set suggests that slight modifications to this set are unlikely to lead to substantially different results on the entire dataset.

\section{V.A. Limitations}

It shall be noted that our predictions are based on expanding the premises about the tasks that computer-controlled equipment can be expected to perform. Hence, we focus on estimating the share of employment that can potentially be substituted by computer capital, from a technological capabilities point of view, over some unspecified number of years. We make no attempt to estimate how many jobs will actually be automated. The actual extent and pace of computerisation will depend on several additional factors which were left unaccounted for.

First, labour saving inventions may only be adopted if the access to cheap labour is scarce or prices of capital are relatively high (Habakkuk, 1962). ${ }^{22} \mathrm{We}$

\footnotetext{
${ }^{22}$ For example, case study evidence suggests that mechanisation in eighteenth century cotton production initially only occurred in Britain because wage levels were much higher relative to
} 
do not account for future wage levels, capital prices or labour shortages. While these factors will impact on the timeline of our predictions, labour is the scarce factor, implying that in the long-run wage levels will increase relative to capital prices, making computerisation increasingly profitable (see, for example, Acemoglu, 2003).

Second, regulatory concerns and political activism may slow down the process of computerisation. The states of California and Nevada are, for example, currently in the process of making legislatory changes to allow for driverless cars. Similar steps will be needed in other states, and in relation to various technologies. The extent and pace of legislatory implementation can furthermore be related to the public acceptance of technological progress. ${ }^{23}$ Although resistance to technological progress has become seemingly less common since the Industrial Revolution, there are recent examples of resistance to technological change. ${ }^{24}$ We avoid making predictions about the legislatory process and the public acceptance of technological progress, and thus the pace of computerisation.

Third, making predictions about technological progress is notoriously difficult (Armstrong and Sotala, 2012). ${ }^{25}$ For this reason, we focus on near-term technological breakthroughs in ML and MR, and avoid making any predictions about the number of years it may take to overcome various engineering bottlenecks to computerisation. Finally, we emphasise that since our probability estimates describe the likelihood of an occupation being fully automated, we do not capture any within-occupation variation resulting from the computerisa-

prices of capital than in other countries (Allen, 2009b). In addition, recent empirical research reveals a causal relationship between the access to cheap labour and mechanisation in agricultural production, in terms of sustained economic transition towards increased mechanisation in areas characterised by low-wage worker out-migration (Hornbeck and Naidu, 2013).

${ }^{23}$ For instance, William Huskisson, former cabinet minister and Member of Parliament for Liverpool, was killed by a steam locomotive during the opening of the Liverpool and Manchester Railway. Nonetheless, this well-publicised incident did anything but dissuade the public from railway transportation technology. By contrast, airship technology is widely recognised as having been popularly abandoned as a consequence of the reporting of the Hindenburg disaster.

${ }^{24}$ Uber, a start-up company connecting passengers with drivers of luxury vehicles, has recently faced pressure from from local regulators, arising from tensions with taxicab services. Furthermore, in 2011 the UK Government scrapped a 12.7 billion GBP project to introduce electronic patient records after resistance from doctors.

${ }^{25}$ Marvin Minsky famously claimed in 1970 that "in from three to eight years we will have a machine with the general intelligence of an average human being". This prediction is yet to materialise. 
tion of tasks that simply free-up time for human labour to perform other tasks. Although it is clear that the impact of productivity gains on employment will vary across occupations and industries, we make no attempt to examine such effects.

\section{CONCLUSIONS}

While computerisation has been historically confined to routine tasks involving explicit rule-based activities (Autor, et al., 2003; Goos, et al., 2009; Autor and Dorn, 2013), algorithms for big data are now rapidly entering domains reliant upon pattern recognition and can readily substitute for labour in a wide range of non-routine cognitive tasks (Brynjolfsson and McAfee, 2011; MGI, 2013). In addition, advanced robots are gaining enhanced senses and dexterity, allowing them to perform a broader scope of manual tasks (IFR, 2012b; Robotics-VO, 2013; MGI, 2013). This is likely to change the nature of work across industries and occupations.

In this paper, we ask the question: how susceptible are current jobs to these technological developments? To assess this, we implement a novel methodology to estimate the probability of computerisation for 702 detailed occupations. Based on these estimates, we examine expected impacts of future computerisation on labour market outcomes, with the primary objective of analysing the number of jobs at risk and the relationship between an occupation's probability of computerisation, wages and educational attainment.

We distinguish between high, medium and low risk occupations, depending on their probability of computerisation. We make no attempt to estimate the number of jobs that will actually be automated, and focus on potential job automatability over some unspecified number of years. According to our estimates around 47 percent of total US employment is in the high risk category. We refer to these as jobs at risk - i.e. jobs we expect could be automated relatively soon, perhaps over the next decade or two.

Our model predicts that most workers in transportation and logistics occupations, together with the bulk of office and administrative support workers, and labour in production occupations, are at risk. These findings are consistent with recent technological developments documented in the literature. More surprisingly, we find that a substantial share of employment in service occupations, 
where most US job growth has occurred over the past decades (Autor and Dorn, 2013), are highly susceptible to computerisation. Additional support for this finding is provided by the recent growth in the market for service robots (MGI, 2013) and the gradually diminishment of the comparative advantage of human labour in tasks involving mobility and dexterity (Robotics-VO, 2013).

Finally, we provide evidence that wages and educational attainment exhibit a strong negative relationship with the probability of computerisation. We note that this finding implies a discontinuity between the nineteenth, twentieth and the twenty-first century, in the impact of capital deepening on the relative demand for skilled labour. While nineteenth century manufacturing technologies largely substituted for skilled labour through the simplification of tasks (Braverman, 1974; Hounshell, 1985; James and Skinner, 1985; Goldin and Katz, 1998), the Computer Revolution of the twentieth century caused a hollowing-out of middle-income jobs (Goos, et al., 2009; Autor and Dorn, 2013). Our model predicts a truncation in the current trend towards labour market polarisation, with computerisation being principally confined to low-skill and low-wage occupations. Our findings thus imply that as technology races ahead, low-skill workers will reallocate to tasks that are non-susceptible to computerisation i.e., tasks requiring creative and social intelligence. For workers to win the race, however, they will have to acquire creative and social skills.

\section{REFERENCES}

Acemoglu, D. (2002). Technical change, inequality, and the labor market. Journal of Economic Literature, vol. 40, no. 1, pp. 7-72.

Acemoglu, D. (2003). Labor- and capital-augmenting technical change. Journal of the European Economic Association, vol. 1, no. 1, pp. 1-37.

Acemoglu, D. and Autor, D. (2011). Skills, tasks and technologies: Implications for employment and earnings. Handbook of labor economics, vol. 4, pp. 1043-1171.

Acemoglu, D. and Robinson, J. (2012). Why nations fail: the origins of power, prosperity, and poverty. Random House Digital, Inc. 
Ackerman, E. and Guizzo, E. (2011). 5 technologies that will shape the web. Spectrum, IEEE, vol. 48, no. 6, pp. 40-45.

Aghion, P. and Howitt, P. (1994). Growth and unemployment. The Review of Economic Studies, vol. 61, no. 3, pp. 477-494.

Allen, R.C. (2009a). Engels' pause: Technical change, capital accumulation, and inequality in the british industrial revolution. Explorations in Economic History, vol. 46, no. 4, pp. 418-435.

Allen, R.C. (2009b). The industrial revolution in miniature: The spinning jenny in Britain, France, and India. The Journal of Economic History, vol. 69, no. 04, pp. 901-927.

Allen, S.G. (2001). Technology and the wage structure. Journal of Labor Economics, vol. 19, no. 2, pp. 440-483.

Armstrong, S. and Sotala, K. (2012). How we're predicting AI - or failing to. Tech. Rep., Oxford: Future of Humanity Institute, Oxford University.

Atack, J., Bateman, F. and Margo, R.A. (2004). Skill intensity and rising wage dispersion in nineteenth-century American manufacturing. The Journal of Economic History, vol. 64, no. 01, pp. 172-192.

Atack, J., Bateman, F. and Margo, R.A. (2008a). Steam power, establishment size, and labor productivity growth in nineteenth century American manufacturing. Explorations in Economic History, vol. 45, no. 2, pp. 185-198.

Atack, J., Haines, M.R. and Margo, R.A. (2008b). Railroads and the rise of the factory: Evidence for the united states, 1850-70. Tech. Rep., NBER Working Paper No. 14410, National Bureau of Economic Research.

Atkinson, A.B. (2008). The changing distribution of earnings in OECD countries. Oxford University Press.

Autor, D. and Dorn, D. (2013). The growth of low skill service jobs and the polarization of the US labor market. American Economic Review, vol. forthcoming. 
Autor, D., Katz, L.F. and Krueger, A.B. (1998). Computing inequality: have computers changed the labor market? The Quarterly Journal of Economics, vol. 113, no. 4, pp. 1169-1213.

Autor, D., Levy, F. and Murnane, R.J. (2003). The skill content of recent technological change: An empirical exploration. The Quarterly Journal of Economics, vol. 118, no. 4, pp. 1279-1333.

Barlow, J. and Ozaki, R. (2005). Building mass customised housing through innovation in the production system: lessons from Japan. Environment and Planning A, vol. 37, no. 1, pp. 9-20.

Beaudry, P., Green, D.A. and Sand, B.M. (2013). The great reversal in the demand for skill and cognitive tasks. Tech. Rep., NBER Working Paper No. 18901, National Bureau of Economic Research.

Beniger, J.R. (1986). The control revolution: Technological and economic origins of the information society. Harvard University Press.

Blinder, A.S. (2009). How many Us jobs might be offshorable? World Economics, vol. 10, no. 2, p. 41.

Blinder, A.S. and Krueger, A.B. (2013). Alternative measures of offshorability: a survey approach. Journal of Labor Economics, vol. 31, no. 2, pp. S97S128.

Bloss, R. (2011). Mobile hospital robots cure numerous logistic needs. Industrial Robot: An International Journal, vol. 38, no. 6, pp. 567-571.

Boden, M.A. (2003). The creative mind: Myths and mechanisms. Routledge.

Braverman, H. (1974). Labor and monopoly capital: The degradation of work in the twentieth century. NYU Press.

Breslow, L., Pritchard, D.E., DeBoer, J., Stump, G.S., Ho, A.D. and Seaton, D. (2013). Studying learning in the worldwide classroom: Research into edx's first mooc. Research \& Practice in Assessment, vol. 8, pp. 13-25.

Bresnahan, T.F. (1999). Computerisation and wage dispersion: an analytical reinterpretation. The Economic Journal, vol. 109, no. 456, pp. 390-415. 
Bresnahan, T.F., Brynjolfsson, E. and Hitt, L.M. (2002). Information technology, workplace organization, and the demand for skilled labor: Firm-level evidence. The Quarterly Journal of Economics, vol. 117, no. 1, pp. 339-376.

Bright, J.R. (1958). Automation and management. Division of Research, Graduate School of Business Administration, Harvard University Boston.

Broekens, J., Heerink, M. and Rosendal, H. (2009). Assistive social robots in elderly care: a review. Gerontechnology, vol. 8, no. 2, pp. 94-103.

Brown, E., Rodenberg, N., Amend, J., Mozeika, A., Steltz, E., Zakin, M.R., Lipson, H. and Jaeger, H.M. (2010). Universal robotic gripper based on the jamming of granular material. Proceedings of the National Academy of Sciences, vol. 107, no. 44, pp. 18809-18814.

Brown, M. and Philips, P. (1986). Craft labor and mechanization in nineteenthcentury American canning. The Journal of Economic History, vol. 46, no. 3, pp. 743-56.

Brynjolfsson, E. and McAfee, A. (2011). Race against the machine: How the digital revolution is accelerating innovation, driving productivity, and irreversibly transforming employment and the economy. Digital Frontier Press Lexington, MA.

Campbell-Kelly, M. (2009). Origin of computing. Scientific American Magazine, vol. 301, no. 3, pp. 62-69.

Chandler, A.D. (1977). The visible hand: The managerial revolution in American business. Harvard University Press.

Charles, K.K., Hurst, E. and Notowidigdo, M.J. (2013). Manufacturing decline, housing booms, and non-employment. Tech. Rep., NBER Working Paper No. 18949, National Bureau of Economic Research.

Churchill, W. and Newman, P. (2012). Practice makes perfect? managing and leveraging visual experiences for lifelong navigation. In: Robotics and $\mathrm{Au}$ tomation (ICRA), 2012 IEEE International Conference on, pp. 4525-4532. IEEE. 
Cisco (2012). Cisco visual networking index. http://www.cisco.com/en/us/ netsol/ns827/networking_solutions_sub_solution.html.

Clark, G. (2008). A farewell to alms: a brief economic history of the world. Princeton University Press.

Clifford, G.D. and Clifton, D. (2012). Wireless technology in disease management and medicine. Annual Review of Medicine, vol. 63, pp. 479-492.

Clifton, L., Clifton, D., Pimentel, M., Watkinson, P. and Tarassenko, L. (2012). Gaussian processes for personalised e-health monitoring with wearable sensors. IEEE Transactions on Biomedical Engineering, vol. 60, pp. 193-197.

Cohn, J. (2013). The robot will see you now. The Atlantic, February 20.

Cortada, J.W. (2000). Before the Computer: IBM, NCR, Burroughs, and Remington Rand and the Industry They Created, 1865-1956. Princeton University Press.

Danziger, S., Levav, J. and Avnaim-Pesso, L. (2011). Extraneous factors in judicial decisions. Proceedings of the National Academy of Sciences, vol. 108, no. 17, pp. 6889-6892.

Davis, S.J. and Haltiwanger, J. (1992). Gross job creation, gross job destruction, and employment reallocation. The Quarterly Journal of Economics, vol. 107, no. 3, pp. 819-863.

Duvenaud, D., Lloyd, J.R., Grosse, R., Tenenbaum, J.B. and Ghahramani, Z. (2013 June). Structure discovery in nonparametric regression through compositional kernel search. In: Proceedings of the 30th International Conference on Machine Learning, arXiv:1206.1846 [stat.ML]. Cambridge, UK.

Epstein, S.R. (1998). Craft guilds, apprenticeship, and technological change in preindustrial europe. Journal of Economic History, vol. 58, pp. 684-713.

Feinstein, C.H. (1998). Pessimism perpetuated: real wages and the standard of living in Britain during and after the industrial revolution. The Journal of Economic History, vol. 58, pp. 625-658. 
Ge, S.S. (2007). Social robotics: Integrating advances in engineering and computer science. In: The 4th annual international conference organized by Electrical Engineering/Electronics, Computer, Telecommunication and Information Technology (ECTI) Association, Chiang Rai, Thailand, May 9â, vol. 12 , p. 2007.

Goldin, C. and Katz, L.F. (1995). The decline of non-competing groups: Changes in the premium to education, 1890 to 1940 . Tech. Rep., NBER Working Paper No. 5202, National Bureau of Economic Research.

Goldin, C. and Katz, L.F. (1998). The origins of technology-skill complementarity. The Quarterly Journal of Economics, vol. 113, no. 3, pp. 693-732.

Goldin, C. and Katz, L.F. (2009). The race between education and technology. Harvard University Press.

Goldin, C. and Sokoloff, K. (1982). Women, children, and industrialization in the early republic: Evidence from the manufacturing censuses. The Journal of Economic History, vol. 42, no. 4, pp. 741-774.

Goos, M. and Manning, A. (2007). Lousy and lovely jobs: The rising polarization of work in Britain. The Review of Economics and Statistics, vol. 89, no. 1 , pp. $118-133$.

Goos, M., Manning, A. and Salomons, A. (2009). Job polarization in europe. The American Economic Review, vol. 99, no. 2, pp. 58-63.

Gordon, R.J. (2012). Is US economic growth over? faltering innovation confronts the six headwinds. Tech. Rep., NBER Working Paper No. 18315, National Bureau of Economic Research.

Gray, R. (2013). Taking technology to task: The skill content of technological change in early twentieth century united states. Explorations in Economic History.

Guizzo, E. (2008 July). Three engineers, hundreds of robots, one warehouse. IEEE Spectrum. http://spectrum.ieee.org/robotics/robotics-software/ three-engineers-hundreds-of-robots-one-warehouse. 
Guizzo, E. (2011). How google's self-driving car works. IEEE Spectrum Online, October, vol. 18.

Habakkuk, H.J. (1962). American and British technology in the nineteenth century: The search for labour-saving inventions. University Press.

Hangal, S. and Lam, M.S. (2002). Tracking down software bugs using automatic anomaly detection. In: Proceedings of the 24th international conference on Software engineering, pp. 291-301. ACM.

Hanson, R. (2001). Economic growth given machine intelligence. Technical Report, University of California, Berkeley.

Hoos, H.H. (2012). Programming by optimization. Communications of the ACM, vol. 55, no. 2, pp. 70-80.

Hornbeck, R. and Naidu, S. (2013). When the levee breaks: Labor mobility and economic development in the American south. The American Economic Review, vol. forthcoming.

Hounshell, D. (1985). From the American system to mass production, 18001932: The development of manufacturing technology in the United States, vol. 4. JHU Press.

Jaimovich, N. and Siu, H.E. (2012). The trend is the cycle: Job polarization and jobless recoveries. Tech. Rep., NBER Working Paper No. 18334, National Bureau of Economic Research.

James, J.A. and Skinner, J.S. (1985). The resolution of the labor-scarcity paradox. The Journal of Economic History, vol. 45, no. 3, pp. 513-540.

Jensen, J.B. and Kletzer, L.G. (2005). Tradable services: Understanding the scope and impact of services offshoring [with comments and discussion]. In: Brookings trade forum, pp. 75-133. JSTOR.

Jensen, J.B. and Kletzer, L.G. (2010). Measuring tradable services and the task content of offshorable services jobs. In: Labor in the new economy, pp. 309-335. University of Chicago Press. 
Kahneman, D., Slovic, P. and Tversky, A. (1982). Judgment under uncertainty. Cambridge University Press.

Katz, L.F. and Margo, R.A. (2013). Technical change and the relative demand for skilled labor: The united states in historical perspective. Tech. Rep., NBER Working Paper No. 18752, National Bureau of Economic Research.

Katz, L.F. and Murphy, K.M. (1992). Changes in relative wages, 1963-1987: supply and demand factors. The Quarterly Journal of Economics, vol. 107, no. 1 , pp. $35-78$.

Kellenbenz, H. (1974). Technology in the age of the scientific revolution, 15001700. The Fontana Economic History of Europe, vol. 2, pp. 177-272.

Keynes, J.M. (1933). Economic possibilities for our grandchildren (1930). Essays in persuasion, pp. 358-73.

Kim, S., Whitehead, E.J. and Zhang, Y. (2008). Classifying software changes: Clean or buggy? Software Engineering, IEEE Transactions on, vol. 34, no. 2, pp. 181-196.

King, S., Bannister, P., Clifton, D. and Tarassenko, L. (2009). Probabilistic approach to the condition monitoring of aerospace engines. Proceedings of the Institution of Mechanical Engineers, Part G: Journal of Aerospace Engineering, vol. 223, no. 5, pp. 533-541.

Krueger, A.B. (1993). How computers have changed the wage structure: evidence from microdata, 1984-1989. The Quarterly Journal of Economics, vol. 108, no. 1, pp. 33-60.

Levy, F. and Murnane, R.J. (2004). The new division of labor: How computers are creating the next job market. Princeton University Press.

Lindert, P.H. and Williamson, J.G. (1983). Reinterpreting Britain's social tables, 1688-1913. Explorations in Economic History, vol. 20, no. 1, pp. 94109.

Linner, T. and Bock, T. (2012). Evolution of large-scale industrialisation and service innovation in Japanese prefabrication industry. Construction Innovation: Information, Process, Management, vol. 12, no. 2, pp. 156-178. 
Livshits, B. and Zimmermann, T. (2005). Dynamine: finding common error patterns by mining software revision histories. In: ACM SIGSOFT Software Engineering Notes, vol. 30, pp. 296-305. ACM.

Louis, P. and Paterson, G. (1986). Biased technical change, scale, and factor substitution in American industry, 1850-1919. The Journal of Economic History, vol. 46, no. 1.

Lucas, R.E. and Prescott, E.C. (1974). Equilibrium search and unemployment. Journal of Economic Theory, vol. 7, no. 2, pp. 188-209.

Mantoux, P. (2006). The industrial revolution in the eighteenth century: An outline of the beginnings of the modern factory system in England. Taylor \& Francis US.

Margo, R.A. (2000). Introduction to wages and labor markets in the United States, 1820-1860. In: Wages and Labor Markets in the United States, 18201860, pp. 1-5. University of Chicago Press.

Markoff, J. (2011). Armies of expensive lawyers replaced by cheaper software.

Markoff, J. (2012 August). Skilled work, without the worker. The New York Times.

Mathibela, B., Osborne, M.A., Posner, I. and Newman, P. (2012). Can priors be trusted? learning to anticipate roadworks. In: Intelligent Transportation Systems (ITSC), 2012 15th International IEEE Conference on, pp. 927-932. IEEE.

Michaels, G., Rauch, F. and Redding, S.J. (2013). Task specialization in US cities from 1880-2000. Tech. Rep., NBER Working Paper No. 18715, National Bureau of Economic Research.

Mims, C. (2010 June). AI that picks stocks better than the pros. MIT Technology Review.

Minka, T.P. (2001). Expectation propagation for approximate Bayesian inference. In: Proceedings of the Seventeenth conference on Uncertainty in artificial intelligence, pp. 362-369. Morgan Kaufmann Publishers Inc. 
Mokyr, J. (1990). The lever of riches: Technological creativity and economic progress. Oxford University Press.

Mokyr, J. (1998). The political economy of technological change. Technological revolutions in Europe, pp. 39-64.

Murphy, K.M., Riddell, W.C. and Romer, P.M. (1998). Wages, skills, and technology in the united states and canada. Tech. Rep., NBER Working Paper No. 6638, National Bureau of Economic Research.

Murphy, K.P. (2012). Machine learning: a probabilistic perspective. The MIT Press.

Nef, J.U. (1957). Coal mining and utilization. A history of technology, vol. 3, pp. 72-88.

Nordhaus, W.D. (2007). Two centuries of productivity growth in computing. The Journal of Economic History, vol. 67, no. 1, p. 128.

North, D.C. and Weingast, B.R. (1989). Constitutions and commitment: the evolution of institutions governing public choice in seventeenth-century england. The Journal of Economic History, vol. 49, no. 04, pp. 803-832.

Ogilvie, S. (2004). Guilds, efficiency, and social capital: evidence from German proto-industry. The Economic History Review, vol. 57, no. 2, pp. 286-333.

Oldenski, L. (2012). Offshoring and the polarization of the US labor market. Tech. Rep., Technical report, Mimeo, Georgetown University.

Osborne, M.A., Garnett, R., Swersky, K. and de Freitas, N. (2012). Prediction and fault detection of environmental signals with uncharacterised faults. In: Twenty-Sixth AAAI Conference on Artificial Intelligence (AAAI-12).

Phua, C., Lee, V., Smith, K. and Gayler, R. (2010). A comprehensive survey of data mining-based fraud detection research. arXiv preprint arXiv:1009.6119.

Picard, R.W. (2010). Affective computing: from laughter to IEEE. Affective Computing, IEEE Transactions on, vol. 1, no. 1, pp. 11-17.

Pissarides, C.A. (2000). Equilibrium unemployment theory. MIT press. 
Plötz, T. and Fink, G.A. (2009). Markov models for offline handwriting recognition: a survey. International Journal on Document Analysis and Recognition (IJDAR), vol. 12, no. 4, pp. 269-298.

Rasmussen, C.E. and Nickisch, H. (2010). Gaussian processes for machine learning (GPML) toolbox. The Journal of Machine Learning Research, vol. 11, pp. 3011-3015.

Rasmussen, C.E. and Williams, C.K.I. (2006). Gaussian Processes for Machine Learning. MIT Press.

Ricardo, D. (1819). The principles of political economy and taxation. World Scientific.

Robotics-VO (2013). A Roadmap for US Robotics. From Internet to Robotics. 2013 Edition. Robotics in the United States of America.

Roy, A.D. (1951). Some thoughts on the distribution of earnings. Oxford Economic Papers, vol. 3, no. 2, pp. 135-146.

Saha, B., Goebel, K., Poll, S. and Christophersen, J. (2007). An integrated approach to battery health monitoring using Bayesian regression and state estimation. In: Autotestcon, 2007 IEEE, pp. 646-653. IEEE.

Sandberg, A. and Bostrom, N. (2008). Whole brain emulation: A roadmap, technical report 2008-3. Tech. Rep., Future of Humanity Institute, Oxford University.

Scherer, K.R., Bänziger, T. and Roesch, E.B. (2010). Blueprint for Affective Computing: A Sourcebook and Manual. Oxford University Press.

Schumpeter, J.A. (1962). Capitalism, socialism and democracy. Harper \& Row New York.

Simonite, T. (2013 June). As data floods in, massive open online courses evolve. MIT Technology Review. http://www.technologyreview.com/news/515396/ as-data-floods-in-massive-open-online-courses-evolve.

Tanner, A. (2007 March). Google seeks world of instant translations. Reuters. http://www.reuters.com/article/2007/03/28/us-google-translate-id। usN1921881520070328. 
CAA (2012). Roadside assistance customers benefit from smart support during peak and after hours. Tech. Rep., SmartAction case study of Canadian Automobile Association Saskatchewan.

IFR (2012a). 68 robots perform farmer's work. Tech. Rep., Case study of Fanuc Robotics Europe S.A., International Federation of Robotics, September 2012.

IFR (2012b). World robotics 2012. Tech. Rep., International Federation of Robotics, August 30, 2012.

MGI (2011). An economy that works: Job creation and America's future. Tech. Rep., McKinsey Global Institute.

MGI (2013). Disruptive technologies: Advances that will transform life, business, and the global economy. Tech. Rep., McKinsey Global Institute.

UC Berkeley School of Information (2003). How much information? 2003. http://www2.sims.berkeley.edu/research/projects/how-much-info-2003.

US Department of Labor (1899). Thirteenth Annual Report of the Commissioner of Labor. Two Volumes, Government Printing Office, Washington, DC.

Veres, S.M., Molnar, L., Lincoln, N.K. and Morice, C.P. (2011). Autonomous vehicle control systems - a review of decision making. Proceedings of the Institution of Mechanical Engineers, Part I: Journal of Systems and Control Engineering, vol. 225, no. 2, pp. 155-195.

Williamson, J.G. and Lindert, P.H. (1980). American inequality: A macroeconomic history, vol. 53. Academic Press New York.

Woolf, B.P. (2010). Building intelligent interactive tutors: Student-centered strategies for revolutionizing e-learning. Morgan Kaufmann. 


\section{APPENDIX}

The table below ranks occupations according to their probability of computerisation (from least- to most-computerisable). Those occupations used as training data are labelled as either ' 0 ' (not computerisable) or ' 1 ' (computerisable), respectively. There are 70 such occupations, 10 percent of the total number of occupations.

\begin{tabular}{|c|c|c|c|c|}
\hline \multicolumn{3}{|c|}{ Computerisable } & \multirow[b]{2}{*}{ soc code } & \multirow[b]{2}{*}{ Occupation } \\
\hline Rank & Probability & Label & & \\
\hline 1. & 0.0028 & & $29-1125$ & Recreational Therapists \\
\hline 2. & 0.003 & & 49-1011 & First-Line Supervisors of Mechanics, Installers, and Repairers \\
\hline 3. & 0.003 & & $11-9161$ & Emergency Management Directors \\
\hline 4. & 0.0031 & & $21-1023$ & Mental Health and Substance Abuse Social Workers \\
\hline 5. & 0.0033 & & $29-1181$ & Audiologists \\
\hline 6. & 0.0035 & & $29-1122$ & Occupational Therapists \\
\hline 7. & 0.0035 & & 29-2091 & Orthotists and Prosthetists \\
\hline 8. & 0.0035 & & $21-1022$ & Healthcare Social Workers \\
\hline 9. & 0.0036 & & $29-1022$ & Oral and Maxillofacial Surgeons \\
\hline 10. & 0.0036 & & $33-1021$ & First-Line Supervisors of Fire Fighting and Prevention Workers \\
\hline 11. & 0.0039 & & $29-1031$ & Dietitians and Nutritionists \\
\hline 12. & 0.0039 & & $11-9081$ & Lodging Managers \\
\hline 13. & 0.004 & & $27-2032$ & Choreographers \\
\hline 14. & 0.0041 & & $41-9031$ & Sales Engineers \\
\hline 15. & 0.0042 & 0 & $29-1060$ & Physicians and Surgeons \\
\hline 16. & 0.0042 & & $25-9031$ & Instructional Coordinators \\
\hline 17. & 0.0043 & & 19-3039 & Psychologists, All Other \\
\hline 18. & 0.0044 & & 33-1012 & First-Line Supervisors of Police and Detectives \\
\hline 19. & 0.0044 & 0 & $29-1021$ & Dentists, General \\
\hline 20. & 0.0044 & & $25-2021$ & Elementary School Teachers, Except Special Education \\
\hline 21. & 0.0045 & & $19-1042$ & Medical Scientists, Except Epidemiologists \\
\hline 22. & 0.0046 & & $11-9032$ & Education Administrators, Elementary and Secondary School \\
\hline 23. & 0.0046 & & $29-1081$ & Podiatrists \\
\hline 24. & 0.0047 & & $19-3031$ & Clinical, Counseling, and School Psychologists \\
\hline 25. & 0.0048 & & 21-1014 & Mental Health Counselors \\
\hline 26. & 0.0049 & & $51-6092$ & Fabric and Apparel Patternmakers \\
\hline 27. & 0.0055 & & $27-1027$ & Set and Exhibit Designers \\
\hline 28. & 0.0055 & & $11-3121$ & Human Resources Managers \\
\hline 29. & 0.0061 & & $39-9032$ & Recreation Workers \\
\hline 30. & 0.0063 & & $11-3131$ & Training and Development Managers \\
\hline 31. & 0.0064 & & $29-1127$ & Speech-Language Pathologists \\
\hline 32. & 0.0065 & & $15-1121$ & Computer Systems Analysts \\
\hline 33. & 0.0067 & 0 & $11-9151$ & Social and Community Service Managers \\
\hline 34. & 0.0068 & & $25-4012$ & Curators \\
\hline 35. & 0.0071 & & $29-9091$ & Athletic Trainers \\
\hline 36. & 0.0073 & & $11-9111$ & Medical and Health Services Managers \\
\hline 37. & 0.0074 & 0 & $25-2011$ & Preschool Teachers, Except Special Education \\
\hline 38. & 0.0075 & & $25-9021$ & Farm and Home Management Advisors \\
\hline 39. & 0.0077 & & $19-3091$ & Anthropologists and Archeologists \\
\hline
\end{tabular}




\begin{tabular}{|c|c|c|c|c|}
\hline \multicolumn{3}{|c|}{ Computerisable } & \multirow[b]{2}{*}{ soc code } & \multirow[b]{2}{*}{ Occupation } \\
\hline Rank & Probability & Label & & \\
\hline 40. & 0.0077 & & $25-2054$ & Special Education Teachers, Secondary School \\
\hline 41. & 0.0078 & & $25-2031$ & $\begin{array}{l}\text { Secondary School Teachers, Except Special and Career/Technical Edu- } \\
\text { cation }\end{array}$ \\
\hline 42. & 0.0081 & 0 & $21-2011$ & Clergy \\
\hline 43. & 0.0081 & & $19-1032$ & Foresters \\
\hline 44. & 0.0085 & & $21-1012$ & Educational, Guidance, School, and Vocational Counselors \\
\hline 45. & 0.0088 & & $25-2032$ & Career/Technical Education Teachers, Secondary School \\
\hline 46. & 0.009 & 0 & $29-1111$ & Registered Nurses \\
\hline 47. & 0.0094 & & $21-1015$ & Rehabilitation Counselors \\
\hline 48. & 0.0095 & & 25-3999 & Teachers and Instructors, All Other \\
\hline 49. & 0.0095 & & $19-4092$ & Forensic Science Technicians \\
\hline 50. & 0.01 & & $39-5091$ & Makeup Artists, Theatrical and Performance \\
\hline 51. & 0.01 & & $17-2121$ & Marine Engineers and Naval Architects \\
\hline 52. & 0.01 & & $11-9033$ & Education Administrators, Postsecondary \\
\hline 53. & 0.011 & & $17-2141$ & Mechanical Engineers \\
\hline 54. & 0.012 & & $29-1051$ & Pharmacists \\
\hline 55. & 0.012 & & $13-1081$ & Logisticians \\
\hline 56. & 0.012 & & $19-1022$ & Microbiologists \\
\hline 57. & 0.012 & & $19-3032$ & Industrial-Organizational Psychologists \\
\hline 58. & 0.013 & & $27-2022$ & Coaches and Scouts \\
\hline 59. & 0.013 & & $11-2022$ & Sales Managers \\
\hline 60. & 0.014 & & $19-2043$ & Hydrologists \\
\hline 61. & 0.014 & & $11-2021$ & Marketing Managers \\
\hline 62. & 0.014 & 0 & $21-1013$ & Marriage and Family Therapists \\
\hline 63. & 0.014 & & $17-2199$ & Engineers, All Other \\
\hline 64. & 0.014 & & $13-1151$ & Training and Development Specialists \\
\hline 65. & 0.014 & & 43-1011 & First-Line Supervisors of Office and Administrative Support Workers \\
\hline 66. & 0.015 & & $19-1029$ & Biological Scientists, All Other \\
\hline 67. & 0.015 & & $11-2031$ & Public Relations and Fundraising Managers \\
\hline 68. & 0.015 & & $27-1014$ & Multimedia Artists and Animators \\
\hline 69. & 0.015 & & $15-1111$ & Computer and Information Research Scientists \\
\hline 70. & 0.015 & 0 & $11-1011$ & Chief Executives \\
\hline 71. & 0.015 & 0 & $11-9031$ & Education Administrators, Preschool and Childcare Center/Program \\
\hline 72. & 0.015 & & $27-2041$ & Music Directors and Composers \\
\hline 73. & 0.016 & & $51-1011$ & First-Line Supervisors of Production and Operating Workers \\
\hline 74. & 0.016 & & $41-3031$ & Securities, Commodities, and Financial Services Sales Agents \\
\hline 75. & 0.016 & & $19-1031$ & Conservation Scientists \\
\hline 76. & 0.016 & & $25-2053$ & Special Education Teachers, Middle School \\
\hline 77. & 0.017 & & $17-2041$ & Chemical Engineers \\
\hline 78. & 0.017 & & $11-9041$ & Architectural and Engineering Managers \\
\hline 79. & 0.017 & & $17-2011$ & Aerospace Engineers \\
\hline 80. & 0.018 & & $11-9121$ & Natural Sciences Managers \\
\hline 81. & 0.018 & & $17-2081$ & Environmental Engineers \\
\hline 82. & 0.018 & & $17-1011$ & Architects, Except Landscape and Naval \\
\hline 83. & 0.018 & & $31-2021$ & Physical Therapist Assistants \\
\hline 84. & 0.019 & 0 & $17-2051$ & Civil Engineers \\
\hline 85. & 0.02 & & 29-1199 & Health Diagnosing and Treating Practitioners, All Other \\
\hline 86. & 0.021 & & $19-1013$ & Soil and Plant Scientists \\
\hline 87. & 0.021 & & $19-2032$ & Materials Scientists \\
\hline
\end{tabular}




\begin{tabular}{|c|c|c|c|c|}
\hline \multicolumn{3}{|c|}{ Computerisable } & \multirow[b]{2}{*}{ SOC code } & \multirow[b]{2}{*}{ Occupation } \\
\hline Rank & Probability & Label & & \\
\hline 88. & 0.021 & & $17-2131$ & Materials Engineers \\
\hline 89. & 0.021 & 0 & $27-1022$ & Fashion Designers \\
\hline 90. & 0.021 & & $29-1123$ & Physical Therapists \\
\hline 91. & 0.021 & & $27-4021$ & Photographers \\
\hline 92. & 0.022 & & $27-2012$ & Producers and Directors \\
\hline 93. & 0.022 & & $27-1025$ & Interior Designers \\
\hline 94. & 0.023 & & $29-1023$ & Orthodontists \\
\hline 95. & 0.023 & & $27-1011$ & Art Directors \\
\hline 96. & 0.025 & & 33-1011 & First-Line Supervisors of Correctional Officers \\
\hline 97. & 0.025 & & $21-2021$ & Directors, Religious Activities and Education \\
\hline 98. & 0.025 & & $17-2072$ & Electronics Engineers, Except Computer \\
\hline 99. & 0.027 & & $19-1021$ & Biochemists and Biophysicists \\
\hline 100. & 0.027 & & 29-1011 & Chiropractors \\
\hline 101. & 0.028 & & $31-2011$ & Occupational Therapy Assistants \\
\hline 102. & 0.028 & & $21-1021$ & Child, Family, and School Social Workers \\
\hline 103. & 0.028 & & $17-2111$ & $\begin{array}{l}\text { Health and Safety Engineers, Except Mining Safety Engineers and In- } \\
\text { spectors }\end{array}$ \\
\hline 104. & 0.029 & & $17-2112$ & Industrial Engineers \\
\hline 105. & 0.029 & & $53-1031$ & $\begin{array}{l}\text { First-Line Supervisors of Transportation and Material-Moving Machine } \\
\text { and Vehicle Operators }\end{array}$ \\
\hline 106. & 0.029 & & $29-2056$ & Veterinary Technologists and Technicians \\
\hline 107. & 0.03 & & 11-3051 & Industrial Production Managers \\
\hline 108. & 0.03 & & $17-3026$ & Industrial Engineering Technicians \\
\hline 109. & 0.03 & & $15-1142$ & Network and Computer Systems Administrators \\
\hline 110. & 0.03 & & $15-1141$ & Database Administrators \\
\hline 111. & 0.03 & & $11-3061$ & Purchasing Managers \\
\hline 112. & 0.032 & & $25-1000$ & Postsecondary Teachers \\
\hline 113. & 0.033 & & $19-2041$ & Environmental Scientists and Specialists, Including Health \\
\hline 114. & 0.033 & 0 & 21-1011 & Substance Abuse and Behavioral Disorder Counselors \\
\hline 115. & 0.035 & 0 & 23-1011 & Lawyers \\
\hline 116. & 0.035 & & $27-1012$ & Craft Artists \\
\hline 117. & 0.035 & & $15-2031$ & Operations Research Analysts \\
\hline 118. & 0.035 & & $11-3021$ & Computer and Information Systems Managers \\
\hline 119. & 0.037 & & $27-1021$ & Commercial and Industrial Designers \\
\hline 120. & 0.037 & & $17-2031$ & Biomedical Engineers \\
\hline 121. & 0.037 & 0 & $13-1121$ & Meeting, Convention, and Event Planners \\
\hline 122. & 0.038 & & $29-1131$ & Veterinarians \\
\hline 123. & 0.038 & & $27-3043$ & Writers and Authors \\
\hline 124. & 0.039 & & $11-2011$ & Advertising and Promotions Managers \\
\hline 125. & 0.039 & & 19-3094 & Political Scientists \\
\hline 126. & 0.04 & & $13-2071$ & Credit Counselors \\
\hline 127. & 0.04 & & 19-3099 & Social Scientists and Related Workers, All Other \\
\hline 128. & 0.041 & & $19-2011$ & Astronomers \\
\hline 129. & 0.041 & & $53-5031$ & Ship Engineers \\
\hline 130. & 0.042 & & $15-1132$ & Software Developers, Applications \\
\hline 131. & 0.042 & & $27-1013$ & Fine Artists, Including Painters, Sculptors, and Illustrators \\
\hline 132. & 0.043 & & $29-2053$ & Psychiatric Technicians \\
\hline 133. & 0.045 & 0 & $17-1012$ & Landscape Architects \\
\hline 134. & 0.045 & & 21-1091 & Health Educators \\
\hline
\end{tabular}




\begin{tabular}{|c|c|c|c|c|}
\hline \multicolumn{3}{|c|}{ Computerisable } & \multirow[b]{2}{*}{ SOC code } & \multirow[b]{2}{*}{ Occupation } \\
\hline Rank & Probability & Label & & \\
\hline 135. & 0.047 & & $15-2021$ & Mathematicians \\
\hline 136. & 0.047 & & $27-1023$ & Floral Designers \\
\hline 137. & 0.047 & & $11-9013$ & Farmers, Ranchers, and Other Agricultural Managers \\
\hline 138. & 0.048 & & $33-2022$ & Forest Fire Inspectors and Prevention Specialists \\
\hline 139. & 0.049 & & $29-2041$ & Emergency Medical Technicians and Paramedics \\
\hline 140. & 0.055 & & $27-3041$ & Editors \\
\hline 141. & 0.055 & & $29-1024$ & Prosthodontists \\
\hline 142. & 0.055 & 0 & 29-9799 & Healthcare Practitioners and Technical Workers, All Other \\
\hline 143. & 0.057 & & $39-7012$ & Travel Guides \\
\hline 144. & 0.058 & & $29-2061$ & Licensed Practical and Licensed Vocational Nurses \\
\hline 145. & 0.059 & & $19-3041$ & Sociologists \\
\hline 146. & 0.06 & & 23-1022 & Arbitrators, Mediators, and Conciliators \\
\hline 147. & 0.061 & & 19-1011 & Animal Scientists \\
\hline 148. & 0.064 & & 39-9041 & Residential Advisors \\
\hline 149. & 0.066 & & $53-1011$ & Aircraft Cargo Handling Supervisors \\
\hline 150. & 0.066 & & $29-1126$ & Respiratory Therapists \\
\hline 151. & 0.067 & & $27-3021$ & Broadcast News Analysts \\
\hline 152. & 0.069 & & $11-3031$ & Financial Managers \\
\hline 153. & 0.07 & & $17-2161$ & Nuclear Engineers \\
\hline 154. & 0.071 & & $11-9021$ & Construction Managers \\
\hline 155. & 0.074 & & $27-2042$ & Musicians and Singers \\
\hline 156. & 0.075 & & 41-1012 & First-Line Supervisors of Non-Retail Sales Workers \\
\hline 157. & 0.076 & & $39-1021$ & First-Line Supervisors of Personal Service Workers \\
\hline 158. & 0.077 & & 19-1012 & Food Scientists and Technologists \\
\hline 159. & 0.08 & 0 & $13-1041$ & Compliance Officers \\
\hline 160. & 0.08 & & $33-3031$ & Fish and Game Wardens \\
\hline 161. & 0.082 & & $27-1024$ & Graphic Designers \\
\hline 162. & 0.083 & & $11-9051$ & Food Service Managers \\
\hline 163. & 0.084 & 0 & $39-9011$ & Childcare Workers \\
\hline 164. & 0.085 & & $39-9031$ & Fitness Trainers and Aerobics Instructors \\
\hline 165. & 0.091 & & $11-9071$ & Gaming Managers \\
\hline 166. & 0.097 & & 49-9051 & Electrical Power-Line Installers and Repairers \\
\hline 167. & 0.098 & & $33-3051$ & Police and Sheriff's Patrol Officers \\
\hline 168. & 0.099 & & $41-3041$ & Travel Agents \\
\hline 169. & 0.1 & 0 & $35-1011$ & Chefs and Head Cooks \\
\hline 170. & 0.1 & & $39-2011$ & Animal Trainers \\
\hline 171. & 0.1 & & 27-3011 & Radio and Television Announcers \\
\hline 172. & 0.1 & 0 & $17-2071$ & Electrical Engineers \\
\hline 173. & 0.1 & & $19-2031$ & Chemists \\
\hline 174. & 0.1 & & 29-2054 & Respiratory Therapy Technicians \\
\hline 175. & 0.1 & 0 & $19-2012$ & Physicists \\
\hline 176. & 0.11 & 0 & $39-5012$ & Hairdressers, Hairstylists, and Cosmetologists \\
\hline 177. & 0.11 & & $27-3022$ & Reporters and Correspondents \\
\hline 178. & 0.11 & & $53-2021$ & Air Traffic Controllers \\
\hline 179. & 0.13 & & $27-2031$ & Dancers \\
\hline 180. & 0.13 & & $29-2033$ & Nuclear Medicine Technologists \\
\hline 181. & 0.13 & & $15-1133$ & Software Developers, Systems Software \\
\hline 182. & 0.13 & & $13-1111$ & Management Analysts \\
\hline 183. & 0.13 & & $29-2051$ & Dietetic Technicians \\
\hline
\end{tabular}




\begin{tabular}{|c|c|c|c|c|}
\hline \multicolumn{3}{|c|}{ Computerisable } & \multirow[b]{2}{*}{ SOC code } & \multirow[b]{2}{*}{ Occupation } \\
\hline Rank & Probability & Label & & \\
\hline 184. & 0.13 & & $19-3051$ & Urban and Regional Planners \\
\hline 185. & 0.13 & & 21-1093 & Social and Human Service Assistants \\
\hline 186. & 0.13 & & $25-3021$ & Self-Enrichment Education Teachers \\
\hline 187. & 0.13 & & $27-4014$ & Sound Engineering Technicians \\
\hline 188. & 0.14 & & 29-1041 & Optometrists \\
\hline 189. & 0.14 & & $17-2151$ & Mining and Geological Engineers, Including Mining Safety Engineers \\
\hline 190. & 0.14 & & 29-1071 & Physician Assistants \\
\hline 191. & 0.15 & & $25-2012$ & Kindergarten Teachers, Except Special Education \\
\hline 192. & 0.15 & & $47-2111$ & Electricians \\
\hline 193. & 0.16 & & $17-2171$ & Petroleum Engineers \\
\hline 194. & 0.16 & & 43-9031 & Desktop Publishers \\
\hline 195. & 0.16 & & $11-1021$ & General and Operations Managers \\
\hline 196. & 0.17 & & $29-9011$ & Occupational Health and Safety Specialists \\
\hline 197. & 0.17 & & $33-2011$ & Firefighters \\
\hline 198. & 0.17 & & $13-2061$ & Financial Examiners \\
\hline 199. & 0.17 & & 47-1011 & First-Line Supervisors of Construction Trades and Extraction Workers \\
\hline 200. & 0.17 & & $25-2022$ & $\begin{array}{l}\text { Middle School Teachers, Except Special and Career/Technical Educa- } \\
\text { tion }\end{array}$ \\
\hline 201. & 0.18 & & $27-3031$ & Public Relations Specialists \\
\hline 202. & 0.18 & & $49-9092$ & Commercial Divers \\
\hline 203. & 0.18 & & $49-9095$ & Manufactured Building and Mobile Home Installers \\
\hline 204. & 0.18 & & $53-2011$ & Airline Pilots, Copilots, and Flight Engineers \\
\hline 205. & 0.19 & & 25-3011 & $\begin{array}{l}\text { Adult Basic and Secondary Education and Literacy Teachers and In- } \\
\text { structors }\end{array}$ \\
\hline 206. & 0.2 & & 19-1041 & Epidemiologists \\
\hline 207. & 0.2 & & $39-4831$ & Funeral Service Managers, Directors, Morticians, and Undertakers \\
\hline 208. & 0.21 & & $15-1179$ & $\begin{array}{l}\text { Information Security Analysts, Web Developers, and Computer Net- } \\
\text { work Architects }\end{array}$ \\
\hline 209. & 0.21 & & $15-2011$ & Actuaries \\
\hline 210. & 0.21 & & $33-9011$ & Animal Control Workers \\
\hline 211. & 0.21 & 0 & $39-6012$ & Concierges \\
\hline 212. & 0.22 & & 15-1799 & Computer Occupations, All Other \\
\hline 213. & 0.22 & & $15-2041$ & Statisticians \\
\hline 214. & 0.22 & & $17-2061$ & Computer Hardware Engineers \\
\hline 215. & 0.23 & & 19-3022 & Survey Researchers \\
\hline 216. & 0.23 & & 13-1199 & Business Operations Specialists, All Other \\
\hline 217. & 0.23 & & $13-2051$ & Financial Analysts \\
\hline 218. & 0.23 & & 29-2037 & Radiologic Technologists and Technicians \\
\hline 219. & 0.23 & & $29-2031$ & Cardiovascular Technologists and Technicians \\
\hline 220. & 0.24 & & 13-1011 & Agents and Business Managers of Artists, Performers, and Athletes \\
\hline 221. & 0.24 & & $17-3029$ & Engineering Technicians, Except Drafters, All Other \\
\hline 222. & 0.25 & & 19-3092 & Geographers \\
\hline 223. & 0.25 & & 29-9012 & Occupational Health and Safety Technicians \\
\hline 224. & 0.25 & & 21-1092 & Probation Officers and Correctional Treatment Specialists \\
\hline 225. & 0.25 & & $17-3025$ & Environmental Engineering Technicians \\
\hline 226. & 0.25 & & $11-9199$ & Managers, All Other \\
\hline 227. & 0.25 & & 53-3011 & $\begin{array}{l}\text { Ambulance Drivers and Attendants, Except Emergency Medical Tech- } \\
\text { nicians }\end{array}$ \\
\hline 228. & 0.25 & & 41-4011 & $\begin{array}{l}\text { Sales Representatives, Wholesale and Manufacturing, Technical and } \\
\text { Scientific Products }\end{array}$ \\
\hline
\end{tabular}




\begin{tabular}{|c|c|c|c|c|}
\hline \multicolumn{3}{|c|}{ Computerisable } & \multirow[b]{2}{*}{ SOC code } & \multirow[b]{2}{*}{ Occupation } \\
\hline Rank & Probability & Label & & \\
\hline 229. & 0.26 & & $25-2023$ & Career/Technical Education Teachers, Middle School \\
\hline 230. & 0.27 & & $53-5021$ & Captains, Mates, and Pilots of Water Vessels \\
\hline 231. & 0.27 & & $31-2012$ & Occupational Therapy Aides \\
\hline 232. & 0.27 & & 49-9062 & Medical Equipment Repairers \\
\hline 233. & 0.28 & & 41-1011 & First-Line Supervisors of Retail Sales Workers \\
\hline 234. & 0.28 & 0 & $27-2021$ & Athletes and Sports Competitors \\
\hline 235. & 0.28 & & $39-1011$ & Gaming Supervisors \\
\hline 236. & 0.29 & & $39-5094$ & Skincare Specialists \\
\hline 237. & 0.29 & & $13-1022$ & Wholesale and Retail Buyers, Except Farm Products \\
\hline 238. & 0.3 & & $19-4021$ & Biological Technicians \\
\hline 239. & 0.3 & & 31-9092 & Medical Assistants \\
\hline 240. & 0.3 & 0 & $19-1023$ & Zoologists and Wildlife Biologists \\
\hline 241. & 0.3 & & $35-2013$ & Cooks, Private Household \\
\hline 242. & 0.31 & & 13-1078 & Human Resources, Training, and Labor Relations Specialists, All Other \\
\hline 243. & 0.31 & & $33-9021$ & Private Detectives and Investigators \\
\hline 244. & 0.31 & & $27-4032$ & Film and Video Editors \\
\hline 245. & 0.33 & & 13-2099 & Financial Specialists, All Other \\
\hline 246. & 0.34 & & $33-3021$ & Detectives and Criminal Investigators \\
\hline 247. & 0.34 & & $29-2055$ & Surgical Technologists \\
\hline 248. & 0.34 & & 29-1124 & Radiation Therapists \\
\hline 249. & 0.35 & 0 & $47-2152$ & Plumbers, Pipefitters, and Steamfitters \\
\hline 250. & 0.35 & 0 & 53-2031 & Flight Attendants \\
\hline 251. & 0.35 & & $29-2032$ & Diagnostic Medical Sonographers \\
\hline 252. & 0.36 & & 33-3011 & Bailiffs \\
\hline 253. & 0.36 & & $51-4012$ & $\begin{array}{l}\text { Computer Numerically Controlled Machine Tool Programmers, Metal } \\
\text { and Plastic }\end{array}$ \\
\hline 254. & 0.36 & & $49-2022$ & $\begin{array}{l}\text { Telecommunications Equipment Installers and Repairers, Except Line } \\
\text { Installers }\end{array}$ \\
\hline 255. & 0.37 & & $51-9051$ & Furnace, Kiln, Oven, Drier, and Kettle Operators and Tenders \\
\hline 256. & 0.37 & & $53-7061$ & Cleaners of Vehicles and Equipment \\
\hline 257. & 0.37 & & $39-4021$ & Funeral Attendants \\
\hline 258. & 0.37 & & $47-5081$ & Helpers-Extraction Workers \\
\hline 259. & 0.37 & & $27-2011$ & Actors \\
\hline 260. & 0.37 & & $53-7111$ & Mine Shuttle Car Operators \\
\hline 261. & 0.38 & & 49-2095 & $\begin{array}{l}\text { Electrical and Electronics Repairers, Powerhouse, Substation, and Re- } \\
\text { lay }\end{array}$ \\
\hline 262. & 0.38 & 1 & $17-1022$ & Surveyors \\
\hline 263. & 0.38 & & $17-3027$ & Mechanical Engineering Technicians \\
\hline 264. & 0.38 & & $53-7064$ & Packers and Packagers, Hand \\
\hline 265. & 0.38 & & 27-3091 & Interpreters and Translators \\
\hline 266. & 0.39 & & $31-1011$ & Home Health Aides \\
\hline 267. & 0.39 & & $51-6093$ & Upholsterers \\
\hline 268. & 0.39 & & $47-4021$ & Elevator Installers and Repairers \\
\hline 269. & 0.39 & & 43-3041 & Gaming Cage Workers \\
\hline 270. & 0.39 & & 25-9011 & Audio-Visual and Multimedia Collections Specialists \\
\hline 271. & 0.4 & 0 & 23-1023 & Judges, Magistrate Judges, and Magistrates \\
\hline 272. & 0.4 & & 49-3042 & Mobile Heavy Equipment Mechanics, Except Engines \\
\hline 273. & 0.4 & & $29-2799$ & Health Technologists and Technicians, All Other \\
\hline 274. & 0.41 & & $45-2041$ & Graders and Sorters, Agricultural Products \\
\hline
\end{tabular}




\begin{tabular}{|c|c|c|c|c|}
\hline \multicolumn{3}{|c|}{ Computerisable } & \multirow[b]{2}{*}{ SOC code } & \multirow[b]{2}{*}{ Occupation } \\
\hline Rank & Probability & Label & & \\
\hline 275. & 0.41 & & $51-2041$ & Structural Metal Fabricators and Fitters \\
\hline 276. & 0.41 & 1 & 23-1012 & Judicial Law Clerks \\
\hline 277. & 0.41 & & 49-2094 & $\begin{array}{l}\text { Electrical and Electronics Repairers, Commercial and Industrial Equip- } \\
\text { ment }\end{array}$ \\
\hline 278. & 0.42 & & $19-4093$ & Forest and Conservation Technicians \\
\hline 279. & 0.42 & & 53-1021 & $\begin{array}{l}\text { First-Line Supervisors of Helpers, Laborers, and Material Movers, } \\
\text { Hand }\end{array}$ \\
\hline 280. & 0.43 & & $39-3093$ & Locker Room, Coatroom, and Dressing Room Attendants \\
\hline 281. & 0.43 & & $19-2099$ & Physical Scientists, All Other \\
\hline 282. & 0.43 & 0 & 19-3011 & Economists \\
\hline 283. & 0.44 & & $19-3093$ & Historians \\
\hline 284. & 0.45 & & $51-9082$ & Medical Appliance Technicians \\
\hline 285. & 0.46 & & 43-4031 & Court, Municipal, and License Clerks \\
\hline 286. & 0.47 & & $13-1141$ & Compensation, Benefits, and Job Analysis Specialists \\
\hline 287. & 0.47 & & 31-1013 & Psychiatric Aides \\
\hline 288. & 0.47 & & $29-2012$ & Medical and Clinical Laboratory Technicians \\
\hline 289. & 0.48 & & $33-2021$ & Fire Inspectors and Investigators \\
\hline 290. & 0.48 & & $17-3021$ & Aerospace Engineering and Operations Technicians \\
\hline 291. & 0.48 & & $27-1026$ & Merchandise Displayers and Window Trimmers \\
\hline 292. & 0.48 & & $47-5031$ & Explosives Workers, Ordnance Handling Experts, and Blasters \\
\hline 293. & 0.48 & & $15-1131$ & Computer Programmers \\
\hline 294. & 0.49 & & 33-9091 & Crossing Guards \\
\hline 295. & 0.49 & & $17-2021$ & Agricultural Engineers \\
\hline 296. & 0.49 & & $47-5061$ & Roof Bolters, Mining \\
\hline 297. & 0.49 & & 49-9052 & Telecommunications Line Installers and Repairers \\
\hline 298. & 0.49 & & $43-5031$ & Police, Fire, and Ambulance Dispatchers \\
\hline 299. & 0.5 & & $53-7033$ & Loading Machine Operators, Underground Mining \\
\hline 300. & 0.5 & & 49-9799 & Installation, Maintenance, and Repair Workers, All Other \\
\hline 301. & 0.5 & & 23-2091 & Court Reporters \\
\hline 302. & 0.51 & & $41-9011$ & Demonstrators and Product Promoters \\
\hline 303. & 0.51 & & 31-9091 & Dental Assistants \\
\hline 304. & 0.52 & & $51-6041$ & Shoe and Leather Workers and Repairers \\
\hline 305. & 0.52 & & $17-3011$ & Architectural and Civil Drafters \\
\hline 306. & 0.53 & & $47-5012$ & Rotary Drill Operators, Oil and Gas \\
\hline 307. & 0.53 & & $47-4041$ & Hazardous Materials Removal Workers \\
\hline 308. & 0.54 & & $39-4011$ & Embalmers \\
\hline 309. & 0.54 & & $47-5041$ & Continuous Mining Machine Operators \\
\hline 310. & 0.54 & & $39-1012$ & Slot Supervisors \\
\hline 311. & 0.54 & & $31-9011$ & Massage Therapists \\
\hline 312. & 0.54 & & 41-3011 & Advertising Sales Agents \\
\hline 313. & 0.55 & & 49-3022 & Automotive Glass Installers and Repairers \\
\hline 314. & 0.55 & & 53-2012 & Commercial Pilots \\
\hline 315. & 0.55 & & $43-4051$ & Customer Service Representatives \\
\hline 316. & 0.55 & & $27-4011$ & Audio and Video Equipment Technicians \\
\hline 317. & 0.56 & & $25-9041$ & Teacher Assistants \\
\hline 318. & 0.57 & & 45-1011 & First-Line Supervisors of Farming, Fishing, and Forestry Workers \\
\hline 319. & 0.57 & & $19-4031$ & Chemical Technicians \\
\hline 320. & 0.57 & & $47-3015$ & Helpers-Pipelayers, Plumbers, Pipefitters, and Steamfitters \\
\hline 321. & 0.57 & 1 & $13-1051$ & Cost Estimators \\
\hline
\end{tabular}




\begin{tabular}{|c|c|c|c|c|}
\hline \multicolumn{3}{|c|}{ Computerisable } & \multirow[b]{2}{*}{ SOC code } & \multirow[b]{2}{*}{ Occupation } \\
\hline Rank & Probability & Label & & \\
\hline 322. & 0.57 & & $33-3052$ & Transit and Railroad Police \\
\hline 323. & 0.57 & & $37-1012$ & $\begin{array}{l}\text { First-Line Supervisors of Landscaping, Lawn Service, and } \\
\text { Groundskeeping Workers }\end{array}$ \\
\hline 324. & 0.58 & & $13-2052$ & Personal Financial Advisors \\
\hline 325. & 0.59 & & $49-9044$ & Millwrights \\
\hline 326. & 0.59 & & $25-4013$ & Museum Technicians and Conservators \\
\hline 327. & 0.59 & & $47-5042$ & Mine Cutting and Channeling Machine Operators \\
\hline 328. & 0.59 & 0 & $11-3071$ & Transportation, Storage, and Distribution Managers \\
\hline 329. & 0.59 & & 49-3092 & Recreational Vehicle Service Technicians \\
\hline 330. & 0.59 & & 49-3023 & Automotive Service Technicians and Mechanics \\
\hline 331. & 0.6 & & $33-3012$ & Correctional Officers and Jailers \\
\hline 332. & 0.6 & & $27-4031$ & Camera Operators, Television, Video, and Motion Picture \\
\hline 333. & 0.6 & & $51-3023$ & Slaughterers and Meat Packers \\
\hline 334. & 0.61 & & 49-2096 & Electronic Equipment Installers and Repairers, Motor Vehicles \\
\hline 335. & 0.61 & & $31-2022$ & Physical Therapist Aides \\
\hline 336. & 0.61 & & 39-3092 & Costume Attendants \\
\hline 337. & 0.61 & 1 & $13-1161$ & Market Research Analysts and Marketing Specialists \\
\hline 338. & 0.61 & & $43-4181$ & Reservation and Transportation Ticket Agents and Travel Clerks \\
\hline 339. & 0.61 & & $51-8031$ & Water and Wastewater Treatment Plant and System Operators \\
\hline 340. & 0.61 & & $19-4099$ & Life, Physical, and Social Science Technicians, All Other \\
\hline 341. & 0.61 & & $51-3093$ & Food Cooking Machine Operators and Tenders \\
\hline 342. & 0.61 & & $51-4122$ & $\begin{array}{l}\text { Welding, Soldering, and Brazing Machine Setters, Operators, and Ten- } \\
\text { ders }\end{array}$ \\
\hline 343. & 0.62 & 1 & $53-5022$ & Motorboat Operators \\
\hline 344. & 0.62 & & $47-2082$ & Tapers \\
\hline 345. & 0.62 & & $47-2151$ & Pipelayers \\
\hline 346. & 0.63 & & $19-2042$ & Geoscientists, Except Hydrologists and Geographers \\
\hline 347. & 0.63 & & 49-9012 & Control and Valve Installers and Repairers, Except Mechanical Door \\
\hline 348. & 0.63 & & 31-9799 & Healthcare Support Workers, All Other \\
\hline 349. & 0.63 & & 35-1012 & First-Line Supervisors of Food Preparation and Serving Workers \\
\hline 350. & 0.63 & & $47-4011$ & Construction and Building Inspectors \\
\hline 351. & 0.64 & & $51-9031$ & Cutters and Trimmers, Hand \\
\hline 352. & 0.64 & & $49-9071$ & Maintenance and Repair Workers, General \\
\hline 353. & 0.64 & & 23-1021 & Administrative Law Judges, Adjudicators, and Hearing Officers \\
\hline 354. & 0.64 & & 43-5081 & Stock Clerks and Order Fillers \\
\hline 355. & 0.64 & & $51-8012$ & Power Distributors and Dispatchers \\
\hline 356. & 0.64 & & $47-2132$ & Insulation Workers, Mechanical \\
\hline 357. & 0.65 & & $19-4061$ & Social Science Research Assistants \\
\hline 358. & 0.65 & & $51-4041$ & Machinists \\
\hline 359. & 0.65 & & $15-1150$ & Computer Support Specialists \\
\hline 360. & 0.65 & & $25-4021$ & Librarians \\
\hline 361. & 0.65 & & 49-2097 & Electronic Home Entertainment Equipment Installers and Repairers \\
\hline 362. & 0.65 & & 49-9021 & Heating, Air Conditioning, and Refrigeration Mechanics and Installers \\
\hline 363. & 0.65 & & $53-7041$ & Hoist and Winch Operators \\
\hline 364. & 0.66 & & $37-2021$ & Pest Control Workers \\
\hline 365. & 0.66 & & $51-9198$ & Helpers-Production Workers \\
\hline 366. & 0.66 & & 43-9111 & Statistical Assistants \\
\hline 367. & 0.66 & & $37-2011$ & Janitors and Cleaners, Except Maids and Housekeeping Cleaners \\
\hline 368. & 0.66 & & 49-3051 & Motorboat Mechanics and Service Technicians \\
\hline
\end{tabular}




\begin{tabular}{|c|c|c|c|c|}
\hline \multicolumn{3}{|c|}{ Computerisable } & \multirow[b]{2}{*}{ SOC code } & \multirow[b]{2}{*}{ Occupation } \\
\hline Rank & Probability & Label & & \\
\hline 369. & 0.67 & & $51-9196$ & Paper Goods Machine Setters, Operators, and Tenders \\
\hline 370. & 0.67 & & $51-4071$ & Foundry Mold and Coremakers \\
\hline 371. & 0.67 & & $19-2021$ & Atmospheric and Space Scientists \\
\hline 372. & 0.67 & 1 & $53-3021$ & Bus Drivers, Transit and Intercity \\
\hline 373. & 0.67 & & 33-9092 & $\begin{array}{l}\text { Lifeguards, Ski Patrol, and Other Recreational Protective Service Work- } \\
\text { ers }\end{array}$ \\
\hline 374. & 0.67 & & $49-9041$ & Industrial Machinery Mechanics \\
\hline 375. & 0.68 & & $43-5052$ & Postal Service Mail Carriers \\
\hline 376. & 0.68 & & $47-5071$ & Roustabouts, Oil and Gas \\
\hline 377. & 0.68 & & $47-2011$ & Boilermakers \\
\hline 378. & 0.68 & & $17-3013$ & Mechanical Drafters \\
\hline 379. & 0.68 & & $29-2021$ & Dental Hygienists \\
\hline 380. & 0.69 & 1 & $53-3033$ & Light Truck or Delivery Services Drivers \\
\hline 381. & 0.69 & 0 & $37-2012$ & Maids and Housekeeping Cleaners \\
\hline 382. & 0.69 & & $51-9122$ & Painters, Transportation Equipment \\
\hline 383. & 0.7 & & $43-4061$ & Eligibility Interviewers, Government Programs \\
\hline 384. & 0.7 & & 49-3093 & Tire Repairers and Changers \\
\hline 385. & 0.7 & & 51-3092 & Food Batchmakers \\
\hline 386. & 0.7 & & $49-2091$ & Avionics Technicians \\
\hline 387. & 0.71 & & 49-3011 & Aircraft Mechanics and Service Technicians \\
\hline 388. & 0.71 & & $53-2022$ & Airfield Operations Specialists \\
\hline 389. & 0.71 & & $51-8093$ & Petroleum Pump System Operators, Refinery Operators, and Gaugers \\
\hline 390. & 0.71 & & 47-4799 & Construction and Related Workers, All Other \\
\hline 391. & 0.71 & & 29-2081 & Opticians, Dispensing \\
\hline 392. & 0.71 & & $51-6011$ & Laundry and Dry-Cleaning Workers \\
\hline 393. & 0.72 & & 39-3091 & Amusement and Recreation Attendants \\
\hline 394. & 0.72 & & $31-9095$ & Pharmacy Aides \\
\hline 395. & 0.72 & & $47-3016$ & Helpers-Roofers \\
\hline 396. & 0.72 & & $53-7121$ & Tank Car, Truck, and Ship Loaders \\
\hline 397. & 0.72 & & $49-9031$ & Home Appliance Repairers \\
\hline 398. & 0.72 & & $47-2031$ & Carpenters \\
\hline 399. & 0.72 & & 27-3012 & Public Address System and Other Announcers \\
\hline 400. & 0.73 & & $51-6063$ & Textile Knitting and Weaving Machine Setters, Operators, and Tenders \\
\hline 401. & 0.73 & & $11-3011$ & Administrative Services Managers \\
\hline 402. & 0.73 & & $47-2121$ & Glaziers \\
\hline 403. & 0.73 & & $51-2021$ & Coil Winders, Tapers, and Finishers \\
\hline 404. & 0.73 & & 49-3031 & Bus and Truck Mechanics and Diesel Engine Specialists \\
\hline 405. & 0.74 & & 49-2011 & Computer, Automated Teller, and Office Machine Repairers \\
\hline 406. & 0.74 & & $39-9021$ & Personal Care Aides \\
\hline 407. & 0.74 & & $27-4012$ & Broadcast Technicians \\
\hline 408. & 0.74 & & 47-3013 & Helpers-Electricians \\
\hline 409. & 0.75 & & $11-9131$ & Postmasters and Mail Superintendents \\
\hline 410. & 0.75 & & $47-2044$ & Tile and Marble Setters \\
\hline 411. & 0.75 & & $47-2141$ & Painters, Construction and Maintenance \\
\hline 412. & 0.75 & & $53-6061$ & Transportation Attendants, Except Flight Attendants \\
\hline 413. & 0.75 & 1 & 17-3022 & Civil Engineering Technicians \\
\hline 414. & 0.75 & & 49-3041 & Farm Equipment Mechanics and Service Technicians \\
\hline 415. & 0.76 & & $25-4011$ & Archivists \\
\hline 416. & 0.76 & & $51-9011$ & Chemical Equipment Operators and Tenders \\
\hline
\end{tabular}




\begin{tabular}{|c|c|c|c|c|}
\hline \multicolumn{3}{|c|}{ Computerisable } & \multirow[b]{2}{*}{ SOC code } & \multirow[b]{2}{*}{ Occupation } \\
\hline Rank & Probability & Label & & \\
\hline 417. & 0.76 & & $49-2092$ & Electric Motor, Power Tool, and Related Repairers \\
\hline 418. & 0.76 & & $45-4021$ & Fallers \\
\hline 419. & 0.77 & & $19-4091$ & Environmental Science and Protection Technicians, Including Health \\
\hline 420. & 0.77 & & 49-9094 & Locksmiths and Safe Repairers \\
\hline 421. & 0.77 & & $37-3013$ & Tree Trimmers and Pruners \\
\hline 422. & 0.77 & & $35-3011$ & Bartenders \\
\hline 423. & 0.77 & & $13-1023$ & Purchasing Agents, Except Wholesale, Retail, and Farm Products \\
\hline 424. & 0.77 & 1 & $35-9021$ & Dishwashers \\
\hline 425. & 0.77 & 0 & $45-3021$ & Hunters and Trappers \\
\hline 426. & 0.78 & & $31-9093$ & Medical Equipment Preparers \\
\hline 427. & 0.78 & & $51-4031$ & $\begin{array}{l}\text { Cutting, Punching, and Press Machine Setters, Operators, and Tenders, } \\
\text { Metal and Plastic }\end{array}$ \\
\hline 428. & 0.78 & & $43-9011$ & Computer Operators \\
\hline 429. & 0.78 & & $51-8092$ & Gas Plant Operators \\
\hline 430. & 0.79 & & $43-5053$ & $\begin{array}{l}\text { Postal Service Mail Sorters, Processors, and Processing Machine Oper- } \\
\text { ators }\end{array}$ \\
\hline 431. & 0.79 & & $53-3032$ & Heavy and Tractor-Trailer Truck Drivers \\
\hline 432. & 0.79 & & $39-5093$ & Shampooers \\
\hline 433. & 0.79 & & $47-2081$ & Drywall and Ceiling Tile Installers \\
\hline 434. & 0.79 & & 49-9098 & Helpers-Installation, Maintenance, and Repair Workers \\
\hline 435. & 0.79 & & 49-3052 & Motorcycle Mechanics \\
\hline 436. & 0.79 & & $51-2011$ & Aircraft Structure, Surfaces, Rigging, and Systems Assemblers \\
\hline 437. & 0.79 & & $45-4022$ & Logging Equipment Operators \\
\hline 438. & 0.79 & & $47-2042$ & Floor Layers, Except Carpet, Wood, and Hard Tiles \\
\hline 439. & 0.8 & & $39-5011$ & Barbers \\
\hline 440. & 0.8 & & $47-5011$ & Derrick Operators, Oil and Gas \\
\hline 441. & 0.81 & 1 & $35-2011$ & Cooks, Fast Food \\
\hline 442. & 0.81 & & 43-9022 & Word Processors and Typists \\
\hline 443. & 0.81 & 1 & $17-3012$ & Electrical and Electronics Drafters \\
\hline 444. & 0.81 & & $17-3024$ & Electro-Mechanical Technicians \\
\hline 445. & 0.81 & & $51-9192$ & $\begin{array}{l}\text { Cleaning, Washing, and Metal Pickling Equipment Operators and Ten- } \\
\text { ders }\end{array}$ \\
\hline 446. & 0.81 & & $11-9141$ & Property, Real Estate, and Community Association Managers \\
\hline 447. & 0.81 & & $43-6013$ & Medical Secretaries \\
\hline 448. & 0.81 & & $51-6021$ & Pressers, Textile, Garment, and Related Materials \\
\hline 449. & 0.82 & & $51-2031$ & Engine and Other Machine Assemblers \\
\hline 450. & 0.82 & & 49-2098 & Security and Fire Alarm Systems Installers \\
\hline 451. & 0.82 & & $49-9045$ & Refractory Materials Repairers, Except Brickmasons \\
\hline 452. & 0.82 & & $39-2021$ & Nonfarm Animal Caretakers \\
\hline 453. & 0.82 & 1 & $47-2211$ & Sheet Metal Workers \\
\hline 454. & 0.82 & & $47-2072$ & Pile-Driver Operators \\
\hline 455. & 0.82 & & $47-2021$ & Brickmasons and Blockmasons \\
\hline 456. & 0.83 & & 45-3011 & Fishers and Related Fishing Workers \\
\hline 457. & 0.83 & & $47-2221$ & Structural Iron and Steel Workers \\
\hline 458. & 0.83 & & $53-4021$ & Railroad Brake, Signal, and Switch Operators \\
\hline 459. & 0.83 & & $53-4031$ & Railroad Conductors and Yardmasters \\
\hline 460. & 0.83 & & $35-2012$ & Cooks, Institution and Cafeteria \\
\hline 461. & 0.83 & & $53-5011$ & Sailors and Marine Oilers \\
\hline 462. & 0.83 & & $51-9023$ & Mixing and Blending Machine Setters, Operators, and Tenders \\
\hline
\end{tabular}




\begin{tabular}{|c|c|c|c|c|}
\hline \multicolumn{3}{|c|}{ Computerisable } & \multirow[b]{2}{*}{ SOC code } & \multirow[b]{2}{*}{ Occupation } \\
\hline Rank & Probability & Label & & \\
\hline 463. & 0.83 & & $47-3011$ & $\begin{array}{l}\text { Helpers-Brickmasons, Blockmasons, Stonemasons, and Tile and Mar- } \\
\text { ble Setters }\end{array}$ \\
\hline 464. & 0.83 & & $47-4091$ & Segmental Pavers \\
\hline 465. & 0.83 & & $47-2131$ & Insulation Workers, Floor, Ceiling, and Wall \\
\hline 466. & 0.83 & & $51-5112$ & Printing Press Operators \\
\hline 467. & 0.83 & & $53-6031$ & Automotive and Watercraft Service Attendants \\
\hline 468. & 0.83 & & $47-4071$ & Septic Tank Servicers and Sewer Pipe Cleaners \\
\hline 469. & 0.83 & & $39-6011$ & Baggage Porters and Bellhops \\
\hline 470. & 0.83 & & 41-2012 & Gaming Change Persons and Booth Cashiers \\
\hline 471. & 0.83 & & $51-4023$ & Rolling Machine Setters, Operators, and Tenders, Metal and Plastic \\
\hline 472. & 0.83 & & $47-2071$ & Paving, Surfacing, and Tamping Equipment Operators \\
\hline 473. & 0.84 & & $51-4111$ & Tool and Die Makers \\
\hline 474. & 0.84 & & $17-3023$ & Electrical and Electronics Engineering Technicians \\
\hline 475. & 0.84 & & $47-2161$ & Plasterers and Stucco Masons \\
\hline 476. & 0.84 & & $51-4192$ & Layout Workers, Metal and Plastic \\
\hline 477. & 0.84 & & $51-4034$ & $\begin{array}{l}\text { Lathe and Turning Machine Tool Setters, Operators, and Tenders, Metal } \\
\text { and Plastic }\end{array}$ \\
\hline 478. & 0.84 & & $33-9032$ & Security Guards \\
\hline 479. & 0.84 & & $51-6052$ & Tailors, Dressmakers, and Custom Sewers \\
\hline 480. & 0.84 & & $53-7073$ & Wellhead Pumpers \\
\hline 481. & 0.84 & & 43-9081 & Proofreaders and Copy Markers \\
\hline 482. & 0.84 & & 33-3041 & Parking Enforcement Workers \\
\hline 483. & 0.85 & & $53-7062$ & Laborers and Freight, Stock, and Material Movers, Hand \\
\hline 484. & 0.85 & & 41-4012 & $\begin{array}{l}\text { Sales Representatives, Wholesale and Manufacturing, Except Technical } \\
\text { and Scientific Products }\end{array}$ \\
\hline 485. & 0.85 & 1 & $43-5041$ & Meter Readers, Utilities \\
\hline 486. & 0.85 & & $51-8013$ & Power Plant Operators \\
\hline 487. & 0.85 & & $51-8091$ & Chemical Plant and System Operators \\
\hline 488. & 0.85 & & $47-5021$ & Earth Drillers, Except Oil and Gas \\
\hline 489. & 0.85 & & $19-4051$ & Nuclear Technicians \\
\hline 490. & 0.86 & & $43-6011$ & Executive Secretaries and Executive Administrative Assistants \\
\hline 491. & 0.86 & & $51-8099$ & Plant and System Operators, All Other \\
\hline 492. & 0.86 & & $35-3041$ & Food Servers, Nonrestaurant \\
\hline 493. & 0.86 & & $51-7041$ & Sawing Machine Setters, Operators, and Tenders, Wood \\
\hline 494. & 0.86 & & $53-4041$ & Subway and Streetcar Operators \\
\hline 495. & 0.86 & & $31-9096$ & Veterinary Assistants and Laboratory Animal Caretakers \\
\hline 496. & 0.86 & & $51-9032$ & Cutting and Slicing Machine Setters, Operators, and Tenders \\
\hline 497. & 0.86 & & $41-9022$ & Real Estate Sales Agents \\
\hline 498. & 0.86 & 1 & $51-4011$ & Computer-Controlled Machine Tool Operators, Metal and Plastic \\
\hline 499. & 0.86 & & $49-9043$ & Maintenance Workers, Machinery \\
\hline 500. & 0.86 & & $43-4021$ & Correspondence Clerks \\
\hline 501. & 0.87 & & $45-2090$ & Miscellaneous Agricultural Workers \\
\hline 502. & 0.87 & & $45-4011$ & Forest and Conservation Workers \\
\hline 503. & 0.87 & & $51-4052$ & Pourers and Casters, Metal \\
\hline 504. & 0.87 & & $47-2041$ & Carpet Installers \\
\hline 505. & 0.87 & & $47-2142$ & Paperhangers \\
\hline 506. & 0.87 & & $13-1021$ & Buyers and Purchasing Agents, Farm Products \\
\hline 507. & 0.87 & & $51-7021$ & Furniture Finishers \\
\hline 508. & 0.87 & & $35-2021$ & Food Preparation Workers \\
\hline
\end{tabular}




\begin{tabular}{|c|c|c|c|c|}
\hline \multicolumn{3}{|c|}{ Computerisable } & \multirow[b]{2}{*}{ SOC code } & \multirow[b]{2}{*}{ Occupation } \\
\hline Rank & Probability & Label & & \\
\hline 509. & 0.87 & & $47-2043$ & Floor Sanders and Finishers \\
\hline 510. & 0.87 & 1 & $53-6021$ & Parking Lot Attendants \\
\hline 511. & 0.87 & & $47-4051$ & Highway Maintenance Workers \\
\hline 512. & 0.88 & & $47-2061$ & Construction Laborers \\
\hline 513. & 0.88 & & $43-5061$ & Production, Planning, and Expediting Clerks \\
\hline 514. & 0.88 & & $51-9141$ & Semiconductor Processors \\
\hline 515. & 0.88 & & $17-1021$ & Cartographers and Photogrammetrists \\
\hline 516. & 0.88 & & $51-4051$ & Metal-Refining Furnace Operators and Tenders \\
\hline 517. & 0.88 & & $51-9012$ & $\begin{array}{l}\text { Separating, Filtering, Clarifying, Precipitating, and Still Machine Set- } \\
\text { ters, Operators, and Tenders }\end{array}$ \\
\hline 518. & 0.88 & & $51-6091$ & $\begin{array}{l}\text { Extruding and Forming Machine Setters, Operators, and Tenders, Syn- } \\
\text { thetic and Glass Fibers }\end{array}$ \\
\hline 519. & 0.88 & & $47-2053$ & Terrazzo Workers and Finishers \\
\hline 520. & 0.88 & & $51-4194$ & Tool Grinders, Filers, and Sharpeners \\
\hline 521. & 0.88 & & 49-3043 & Rail Car Repairers \\
\hline 522. & 0.89 & & $51-3011$ & Bakers \\
\hline 523. & 0.89 & 1 & $31-9094$ & Medical Transcriptionists \\
\hline 524. & 0.89 & & $47-2022$ & Stonemasons \\
\hline 525. & 0.89 & & $53-3022$ & Bus Drivers, School or Special Client \\
\hline 526. & 0.89 & 1 & 27-3042 & Technical Writers \\
\hline 527. & 0.89 & & 49-9096 & Riggers \\
\hline 528. & 0.89 & & $47-4061$ & Rail-Track Laying and Maintenance Equipment Operators \\
\hline 529. & 0.89 & & $51-8021$ & Stationary Engineers and Boiler Operators \\
\hline 530. & 0.89 & 1 & $51-6031$ & Sewing Machine Operators \\
\hline 531. & 0.89 & 1 & $53-3041$ & Taxi Drivers and Chauffeurs \\
\hline 532. & 0.9 & 1 & $43-4161$ & Human Resources Assistants, Except Payroll and Timekeeping \\
\hline 533. & 0.9 & & 29-2011 & Medical and Clinical Laboratory Technologists \\
\hline 534. & 0.9 & & $47-2171$ & Reinforcing Iron and Rebar Workers \\
\hline 535. & 0.9 & & $47-2181$ & Roofers \\
\hline 536. & 0.9 & & $53-7021$ & Crane and Tower Operators \\
\hline 537. & 0.9 & & $53-6041$ & Traffic Technicians \\
\hline 538. & 0.9 & & $53-6051$ & Transportation Inspectors \\
\hline 539. & 0.9 & & $51-4062$ & Patternmakers, Metal and Plastic \\
\hline 540. & 0.9 & & $51-9195$ & Molders, Shapers, and Casters, Except Metal and Plastic \\
\hline 541. & 0.9 & & $13-2021$ & Appraisers and Assessors of Real Estate \\
\hline 542. & 0.9 & & $53-7072$ & Pump Operators, Except Wellhead Pumpers \\
\hline 543. & 0.9 & & 49-9097 & Signal and Track Switch Repairers \\
\hline 544. & 0.91 & & $39-3012$ & Gaming and Sports Book Writers and Runners \\
\hline 545. & 0.91 & & 49-9063 & Musical Instrument Repairers and Tuners \\
\hline 546. & 0.91 & & $39-7011$ & Tour Guides and Escorts \\
\hline 547. & 0.91 & & 49-9011 & Mechanical Door Repairers \\
\hline 548. & 0.91 & & $51-3091$ & $\begin{array}{l}\text { Food and Tobacco Roasting, Baking, and Drying Machine Operators } \\
\text { and Tenders }\end{array}$ \\
\hline 549. & 0.91 & & $53-7071$ & Gas Compressor and Gas Pumping Station Operators \\
\hline 550. & 0.91 & & 29-2071 & Medical Records and Health Information Technicians \\
\hline 551. & 0.91 & & $51-9121$ & $\begin{array}{l}\text { Coating, Painting, and Spraying Machine Setters, Operators, and Ten- } \\
\text { ders }\end{array}$ \\
\hline 552. & 0.91 & & $51-4081$ & $\begin{array}{l}\text { Multiple Machine Tool Setters, Operators, and Tenders, Metal and Plas- } \\
\text { tic }\end{array}$ \\
\hline
\end{tabular}




\begin{tabular}{|c|c|c|c|c|}
\hline \multicolumn{3}{|c|}{ Computerisable } & \multirow[b]{2}{*}{ SOC code } & \multirow[b]{2}{*}{ Occupation } \\
\hline Rank & Probability & Label & & \\
\hline 553. & 0.91 & & $53-4013$ & Rail Yard Engineers, Dinkey Operators, and Hostlers \\
\hline 554. & 0.91 & & $49-2093$ & $\begin{array}{l}\text { Electrical and Electronics Installers and Repairers, Transportation } \\
\text { Equipment }\end{array}$ \\
\hline 555. & 0.91 & & $35-9011$ & Dining Room and Cafeteria Attendants and Bartender Helpers \\
\hline 556. & 0.91 & & $51-4191$ & $\begin{array}{l}\text { Heat Treating Equipment Setters, Operators, and Tenders, Metal and } \\
\text { Plastic }\end{array}$ \\
\hline 557. & 0.91 & & $19-4041$ & Geological and Petroleum Technicians \\
\hline 558. & 0.91 & & $49-3021$ & Automotive Body and Related Repairers \\
\hline 559. & 0.91 & & $51-7032$ & Patternmakers, Wood \\
\hline 560. & 0.91 & & $51-4021$ & $\begin{array}{l}\text { Extruding and Drawing Machine Setters, Operators, and Tenders, Metal } \\
\text { and Plastic }\end{array}$ \\
\hline 561. & 0.92 & & $43-9071$ & Office Machine Operators, Except Computer \\
\hline 562. & 0.92 & & 29-2052 & Pharmacy Technicians \\
\hline 563. & 0.92 & & $43-4131$ & Loan Interviewers and Clerks \\
\hline 564. & 0.92 & & $53-7031$ & Dredge Operators \\
\hline 565. & 0.92 & & 41-3021 & Insurance Sales Agents \\
\hline 566. & 0.92 & & $51-7011$ & Cabinetmakers and Bench Carpenters \\
\hline 567. & 0.92 & & $51-9123$ & Painting, Coating, and Decorating Workers \\
\hline 568. & 0.92 & & $47-4031$ & Fence Erectors \\
\hline 569. & 0.92 & & $51-4193$ & $\begin{array}{l}\text { Plating and Coating Machine Setters, Operators, and Tenders, Metal } \\
\text { and Plastic }\end{array}$ \\
\hline 570. & 0.92 & & $41-2031$ & Retail Salespersons \\
\hline 571. & 0.92 & & $35-3021$ & Combined Food Preparation and Serving Workers, Including Fast Food \\
\hline 572. & 0.92 & & $51-9399$ & Production Workers, All Other \\
\hline 573. & 0.92 & & 47-3012 & Helpers-Carpenters \\
\hline 574. & 0.93 & & $51-9193$ & Cooling and Freezing Equipment Operators and Tenders \\
\hline 575. & 0.93 & & $51-2091$ & Fiberglass Laminators and Fabricators \\
\hline 576. & 0.93 & & $47-5013$ & Service Unit Operators, Oil, Gas, and Mining \\
\hline 577. & 0.93 & & $53-7011$ & Conveyor Operators and Tenders \\
\hline 578. & 0.93 & & 49-3053 & Outdoor Power Equipment and Other Small Engine Mechanics \\
\hline 579. & 0.93 & & $53-4012$ & Locomotive Firers \\
\hline 580. & 0.93 & & $53-7063$ & Machine Feeders and Offbearers \\
\hline 581. & 0.93 & & $51-4061$ & Model Makers, Metal and Plastic \\
\hline 582. & 0.93 & & $49-2021$ & Radio, Cellular, and Tower Equipment Installers and Repairs \\
\hline 583. & 0.93 & & $51-3021$ & Butchers and Meat Cutters \\
\hline 584. & 0.93 & & $51-9041$ & $\begin{array}{l}\text { Extruding, Forming, Pressing, and Compacting Machine Setters, Oper- } \\
\text { ators, and Tenders }\end{array}$ \\
\hline 585. & 0.93 & & $53-7081$ & Refuse and Recyclable Material Collectors \\
\hline 586. & 0.93 & 1 & $13-2081$ & Tax Examiners and Collectors, and Revenue Agents \\
\hline 587. & 0.93 & & $51-4022$ & Forging Machine Setters, Operators, and Tenders, Metal and Plastic \\
\hline 588. & 0.93 & 1 & $53-7051$ & Industrial Truck and Tractor Operators \\
\hline 589. & 0.94 & 1 & $13-2011$ & Accountants and Auditors \\
\hline 590. & 0.94 & & $51-4032$ & $\begin{array}{l}\text { Drilling and Boring Machine Tool Setters, Operators, and Tenders, } \\
\text { Metal and Plastic }\end{array}$ \\
\hline 591. & 0.94 & & $43-9051$ & Mail Clerks and Mail Machine Operators, Except Postal Service \\
\hline 592. & 0.94 & 0 & $35-3031$ & Waiters and Waitresses \\
\hline 593. & 0.94 & & $51-3022$ & Meat, Poultry, and Fish Cutters and Trimmers \\
\hline 594. & 0.94 & & $13-2031$ & Budget Analysts \\
\hline 595. & 0.94 & & $47-2051$ & Cement Masons and Concrete Finishers \\
\hline
\end{tabular}




\begin{tabular}{|c|c|c|c|c|}
\hline \multicolumn{3}{|c|}{ Computerisable } & \multirow[b]{2}{*}{ soc code } & \multirow[b]{2}{*}{ Occupation } \\
\hline Rank & Probability & Label & & \\
\hline 596. & 0.94 & & 49-3091 & Bicycle Repairers \\
\hline 597. & 0.94 & & 49-9091 & Coin, Vending, and Amusement Machine Servicers and Repairers \\
\hline 598. & 0.94 & & $51-4121$ & Welders, Cutters, Solderers, and Brazers \\
\hline 599. & 0.94 & 1 & $43-5021$ & Couriers and Messengers \\
\hline 600. & 0.94 & & $43-4111$ & Interviewers, Except Eligibility and Loan \\
\hline 601. & 0.94 & & $35-2015$ & Cooks, Short Order \\
\hline 602. & 0.94 & & $53-7032$ & Excavating and Loading Machine and Dragline Operators \\
\hline 603. & 0.94 & & 47-3014 & Helpers-Painters, Paperhangers, Plasterers, and Stucco Masons \\
\hline 604. & 0.94 & & $43-4081$ & Hotel, Motel, and Resort Desk Clerks \\
\hline 605. & 0.94 & & $51-9197$ & Tire Builders \\
\hline 606. & 0.94 & & $41-9091$ & $\begin{array}{l}\text { Door-to-Door Sales Workers, News and Street Vendors, and Related } \\
\text { Workers }\end{array}$ \\
\hline 607. & 0.94 & & $37-1011$ & First-Line Supervisors of Housekeeping and Janitorial Workers \\
\hline 608. & 0.94 & & $45-2011$ & Agricultural Inspectors \\
\hline 609. & 0.94 & 1 & 23-2011 & Paralegals and Legal Assistants \\
\hline 610. & 0.95 & & $39-5092$ & Manicurists and Pedicurists \\
\hline 611. & 0.95 & & $43-5111$ & Weighers, Measurers, Checkers, and Samplers, Recordkeeping \\
\hline 612. & 0.95 & & $51-6062$ & Textile Cutting Machine Setters, Operators, and Tenders \\
\hline 613. & 0.95 & & 43-3011 & Bill and Account Collectors \\
\hline 614. & 0.95 & & $51-8011$ & Nuclear Power Reactor Operators \\
\hline 615. & 0.95 & & $33-9031$ & Gaming Surveillance Officers and Gaming Investigators \\
\hline 616. & 0.95 & & $43-4121$ & Library Assistants, Clerical \\
\hline 617. & 0.95 & & $47-2073$ & Operating Engineers and Other Construction Equipment Operators \\
\hline 618. & 0.95 & & $51-5113$ & Print Binding and Finishing Workers \\
\hline 619. & 0.95 & & $45-2021$ & Animal Breeders \\
\hline 620. & 0.95 & & $51-4072$ & $\begin{array}{l}\text { Molding, Coremaking, and Casting Machine Setters, Operators, and } \\
\text { Tenders, Metal and Plastic }\end{array}$ \\
\hline 621. & 0.95 & 1 & $51-2022$ & Electrical and Electronic Equipment Assemblers \\
\hline 622. & 0.95 & & $51-9191$ & Adhesive Bonding Machine Operators and Tenders \\
\hline 623. & 0.95 & & $37-3011$ & Landscaping and Groundskeeping Workers \\
\hline 624. & 0.95 & & $51-4033$ & $\begin{array}{l}\text { Grinding, Lapping, Polishing, and Buffing Machine Tool Setters, Oper- } \\
\text { ators, and Tenders, Metal and Plastic }\end{array}$ \\
\hline 625. & 0.95 & & $43-5051$ & Postal Service Clerks \\
\hline 626. & 0.95 & & $51-9071$ & Jewelers and Precious Stone and Metal Workers \\
\hline 627. & 0.96 & & $43-5032$ & Dispatchers, Except Police, Fire, and Ambulance \\
\hline 628. & 0.96 & & $43-4171$ & Receptionists and Information Clerks \\
\hline 629. & 0.96 & & 43-9061 & Office Clerks, General \\
\hline 630. & 0.96 & & $11-3111$ & Compensation and Benefits Managers \\
\hline 631. & 0.96 & 1 & 43-2011 & Switchboard Operators, Including Answering Service \\
\hline 632. & 0.96 & & $35-3022$ & Counter Attendants, Cafeteria, Food Concession, and Coffee Shop \\
\hline 633. & 0.96 & & $47-5051$ & Rock Splitters, Quarry \\
\hline 634. & 0.96 & & 43-6014 & $\begin{array}{l}\text { Secretaries and Administrative Assistants, Except Legal, Medical, and } \\
\text { Executive }\end{array}$ \\
\hline 635. & 0.96 & & $17-3031$ & Surveying and Mapping Technicians \\
\hline 636. & 0.96 & & $51-7031$ & Model Makers, Wood \\
\hline 637. & 0.96 & & $51-6064$ & $\begin{array}{l}\text { Textile Winding, Twisting, and Drawing Out Machine Setters, Opera- } \\
\text { tors, and Tenders }\end{array}$ \\
\hline 638. & 0.96 & & $53-4011$ & Locomotive Engineers \\
\hline 639. & 0.96 & 1 & $39-3011$ & Gaming Dealers \\
\hline
\end{tabular}




\begin{tabular}{|c|c|c|c|c|}
\hline \multicolumn{3}{|c|}{ Computerisable } & \multirow[b]{2}{*}{ SOC code } & \multirow[b]{2}{*}{ Occupation } \\
\hline Rank & Probability & Label & & \\
\hline 640. & 0.96 & & $49-9093$ & Fabric Menders, Except Garment \\
\hline 641. & 0.96 & & $35-2014$ & Cooks, Restaurant \\
\hline 642. & 0.96 & & 39-3031 & Ushers, Lobby Attendants, and Ticket Takers \\
\hline 643. & 0.96 & & 43-3021 & Billing and Posting Clerks \\
\hline 644. & 0.97 & & $53-6011$ & Bridge and Lock Tenders \\
\hline 645. & 0.97 & & $51-7042$ & Woodworking Machine Setters, Operators, and Tenders, Except Sawing \\
\hline 646. & 0.97 & & $51-2092$ & Team Assemblers \\
\hline 647. & 0.97 & & $51-6042$ & Shoe Machine Operators and Tenders \\
\hline 648. & 0.97 & & $51-2023$ & Electromechanical Equipment Assemblers \\
\hline 649. & 0.97 & 1 & 13-1074 & Farm Labor Contractors \\
\hline 650. & 0.97 & & $51-6061$ & Textile Bleaching and Dyeing Machine Operators and Tenders \\
\hline 651. & 0.97 & & $51-9081$ & Dental Laboratory Technicians \\
\hline 652. & 0.97 & & $51-9021$ & $\begin{array}{l}\text { Crushing, Grinding, and Polishing Machine Setters, Operators, and } \\
\text { Tenders }\end{array}$ \\
\hline 653. & 0.97 & & $51-9022$ & Grinding and Polishing Workers, Hand \\
\hline 654. & 0.97 & & $37-3012$ & Pesticide Handlers, Sprayers, and Applicators, Vegetation \\
\hline 655. & 0.97 & & $45-4023$ & Log Graders and Scalers \\
\hline 656. & 0.97 & & $51-9083$ & Ophthalmic Laboratory Technicians \\
\hline 657. & 0.97 & 1 & $41-2011$ & Cashiers \\
\hline 658. & 0.97 & & $49-9061$ & Camera and Photographic Equipment Repairers \\
\hline 659. & 0.97 & & 39-3021 & Motion Picture Projectionists \\
\hline 660. & 0.97 & & $51-5111$ & Prepress Technicians and Workers \\
\hline 661. & 0.97 & & $41-2021$ & Counter and Rental Clerks \\
\hline 662. & 0.97 & 1 & $43-4071$ & File Clerks \\
\hline 663. & 0.97 & & $41-9021$ & Real Estate Brokers \\
\hline 664. & 0.97 & & 43-2021 & Telephone Operators \\
\hline 665. & 0.97 & & $19-4011$ & Agricultural and Food Science Technicians \\
\hline 666. & 0.97 & & $43-3051$ & Payroll and Timekeeping Clerks \\
\hline 667. & 0.97 & 1 & $43-4041$ & Credit Authorizers, Checkers, and Clerks \\
\hline 668. & 0.97 & & $35-9031$ & Hosts and Hostesses, Restaurant, Lounge, and Coffee Shop \\
\hline 669. & 0.98 & & 41-9012 & Models \\
\hline 670. & 0.98 & & $51-9061$ & Inspectors, Testers, Sorters, Samplers, and Weighers \\
\hline 671. & 0.98 & & 43-3031 & Bookkeeping, Accounting, and Auditing Clerks \\
\hline 672. & 0.98 & & 43-6012 & Legal Secretaries \\
\hline 673. & 0.98 & & $27-4013$ & Radio Operators \\
\hline 674. & 0.98 & & 53-3031 & Driver/Sales Workers \\
\hline 675. & 0.98 & 1 & $13-1031$ & Claims Adjusters, Examiners, and Investigators \\
\hline 676. & 0.98 & & $41-2022$ & Parts Salespersons \\
\hline 677. & 0.98 & 1 & $13-2041$ & Credit Analysts \\
\hline 678. & 0.98 & & $51-4035$ & $\begin{array}{l}\text { Milling and Planing Machine Setters, Operators, and Tenders, Metal } \\
\text { and Plastic }\end{array}$ \\
\hline 679. & 0.98 & & $43-5071$ & Shipping, Receiving, and Traffic Clerks \\
\hline 680. & 0.98 & & 43-3061 & Procurement Clerks \\
\hline 681. & 0.98 & & $51-9111$ & Packaging and Filling Machine Operators and Tenders \\
\hline 682. & 0.98 & & $51-9194$ & Etchers and Engravers \\
\hline 683. & 0.98 & & 43-3071 & Tellers \\
\hline 684. & 0.98 & & $27-2023$ & Umpires, Referees, and Other Sports Officials \\
\hline 685. & 0.98 & & $13-1032$ & Insurance Appraisers, Auto Damage \\
\hline 686. & 0.98 & 1 & $13-2072$ & Loan Officers \\
\hline
\end{tabular}




\begin{tabular}{lllll}
\hline \multicolumn{3}{c}{ Computerisable } & & \\
\cline { 1 - 2 } Rank & Probability & Label & Soc code & Occupation \\
\hline 687. & 0.98 & $43-4151$ & Order Clerks \\
688. & 0.98 & $43-4011$ & Brokerage Clerks \\
689. & 0.98 & $43-9041$ & Insurance Claims and Policy Processing Clerks \\
690. & 0.98 & & $51-2093$ & Timing Device Assemblers and Adjusters \\
691. & 0.99 & 1 & $43-9021$ & Data Entry Keyers \\
692. & 0.99 & & $25-4031$ & Library Technicians \\
693. & 0.99 & & $43-4141$ & New Accounts Clerks \\
694. & 0.99 & & $51-9151$ & Photographic Process Workers and Processing Machine Operators \\
695. & 0.99 & & $13-2082$ & Tax Preparers \\
696. & 0.99 & & $43-5011$ & Cargo and Freight Agents \\
697. & 0.99 & & $49-9064$ & Watch Repairers \\
698. & 0.99 & 1 & $13-2053$ & Insurance Underwriters \\
699. & 0.99 & & $15-2091$ & Mathematical Technicians \\
700. & 0.99 & & $51-6051$ & Sewers, Hand \\
701. & 0.99 & & $23-2093$ & Title Examiners, Abstractors, and Searchers \\
702. & 0.99 & & $41-9041$ & Telemarketers \\
\hline
\end{tabular}

